\title{
Preliminary Method for Prospective Analysis of the Circadian Efficacy of (Day)Light with Applications to Healthcare Architecture
}

Christopher S. Pechacek, Assoc. AIA ${ }^{1}$, Marilyne Andersen, $\mathrm{PhD}^{1, *}$, Steven W. Lockley, $\mathrm{PhD}^{2}$

${ }^{1}$ Building Technology Program, Department of Architecture, Massachusetts Institute of Technology, Cambridge, USA

2Division of Sleep Medicine, Brigham and Women's Hospital, Harvard Medical School, Boston, USA

* Corresponding author. Prof. M. Andersen, MIT Room 5-418, 77

Massachusetts Avenue, Cambridge MA 02139, USA. Phone: +1 617

253 7714. Fax: +1 617253 6152. Email: mand@mit.edu.

\begin{abstract}
Recent studies have attempted to link environmental cues, such as lighting, with human performance and health, and initial findings seem to indicate a positive correlation between the two. Light is the major environmental time cue that resets the human circadian pacemaker, an endogenous clock in the hypothalamus that controls the timing of many 24-hour rhythms in physiology and behavior. Insufficient or inappropriate light exposure can disrupt normal circadian rhythms which may result in adverse consequences for human performance, health and safety.

This paper addresses the problem of prospective analysis of building architecture for circadian stimulus potential based on the state of the art in photobiology. Three variables were considered in this analysis: lighting intensity, timing, and spectrum. Intensity is a standard design tool frequently used in illuminating engineering. Timing and spectrum are not commonplace considerations, so the analysis that follows proposes tools to quantitatively address these additional requirements.
\end{abstract}

Outcomes of photobiology research were used in this paper to define threshold values for illumination in terms of spectrum, intensity, and timing of light at the human eye, and were translated into goals for simulation - and ultimately for building design. In particular, the climate-based Daylight Autonomy (DA) metric was chosen to simulate the probabilistic and temporal potential of daylight for human health needs.

The developed method was applied to study the impact of key architectural decisions on achieving prescribed stimulus of the circadian system in a hospital patient room design; studied variables included orientation, window size, and glazing material. A healthcare setting was specifically chosen with the intent of follow-on research to validate our findings with actual patient outcome data. 


\section{KEYWORDS}

Circadian, daylight, evidence-based design, melatonin, metrics, health

\section{INTRODUCTION}

Light affects humans on physical (Bergman and others 1995), physiological (Lockley 2008, In Press), and psychological levels (Farley $\&$ Veitch 2001), though the results are not always conclusive (Knez 2001). As the relationship is complex, some level of simplification is necessary in order to make an objective assessment of the human health-light connection and we chose to pursue the human healthlight connection from a physiological perspective.

The use of physiology as inspiration in architectural design finds precedent in the work of architects such as Richard Neutra (Neutra 2007). By studying the relationship between human physiology and light, research in photobiology, especially circadian photoreception, has advanced to a point where specific lighting implications can be proposed. Previous research has reported dramatic healthcare outcomes in relation to the quality of daylit environments (Walsh and others 2005) (Beauchemin \& Hays 1998) (Wilson 1972) although the mechanism and photoreceptor systems mediating these effects are as yet unknown.

Many aspects of human physiology and behavior are dominated by 24-h rhythms that have a major impact on our health and well-being. For example, sleep-wake cycles, alertness and performance patterns, core body temperature rhythms and the production of the hormones melatonin and cortisol are all regulated by an endogenous near-24hour oscillator in the suprachiasmatic nuclei (SCN) of the hypothalamus. The cells in these nuclei spontaneously generate rhythms with a period close to, but not exactly, 24 hours, and are therefore synchronized to environmental time by the 24-hour lightdark cycle. Light information is captured exclusively by the eyes using specialized retinal photoreceptors located in the ganglion cell layer, separate from the rod and cone photoreceptors used for vision. These cells contain a novel photopigment called melanopsin and project directly to the SCN via a dedicated neural pathway, the retinohypothalamic tract (RHT) (Provencio and others 2000). Each day the light-dark cycle resets the internal clock, which in turn, synchronizes the physiology and behavior controlled by the clock (Lockley 2008, In Press). It is this time-index of light which is of interest for this research.

Melanopsin is most sensitive to short-wavelength (blue) visible light $\left(\lambda_{\max } \sim 80 \mathrm{~nm}\right)$ and studies on humans and animals have concluded that short-wavelength light maximally stimulates a wide range of physiological responses associated with the neuroendocrine and

neurobiological systems. These include resetting the timing of the 
circadian pacemaker, suppressing nocturnal melatonin production, and improving subjective and objective measures of alertness (Lockley and others 2006) (Peirson \& Foster 2006) (Brainard \& Hanifin 2005) (Lockley and others 2003). Figure 1 shows the action spectra of the human three-cone photic visual system for individual cones [V $(\lambda)]$, scotopic low-light vision $\left[\mathrm{V}^{\prime}(\lambda)\right]$, and the presumed action spectrum based on currently available data for the non-visual 'circadian' photoreceptor system, here referred to as circadian stimulus $[C(\lambda)]$. Since circadian photoreception sensitivity $[C(\lambda)]$ peaks at approximately $480 \mathrm{~nm}$, photopic illumination measures such as lux or footcandles, which are calibrated for the human photopic system, $\left(\mathrm{V}(\lambda), \lambda_{\max } 555 \mathrm{~nm}\right.$ ) (Sharpe and others 2005), do not accurately express circadian stimulus (Lockley and others 2003) (Fig. 1).

In addition to spectrum, the intensity of the source is critical to achieving circadian effect. As reported by Cajochen and others. (2000), night-time light exposure from a 4100K lamp received at the cornea (vertical illuminance) at $\sim 200-500$ lux was sufficient to raise subjective alertness to the peak level tested (Cajochen and others 2000). Near-maximal suppression of melatonin production and circadian phase resetting was simultaneously achieved at a similar vertical illumination (Zeitzer and others 2000). While the relative illuminance of a single light source may correlate with the relative circadian stimulus, for artificial sources the short-wavelength content of lamps varies based on manufacturer and model. So, illuminance measurements from one source do not reflect the circadian stimulus from a different source at the same illuminance, and therefore the spectrum of each source must be considered specifically. In addition to spectrum and intensity, light timing, duration, pattern and prior exposure history are also critical aspects for determining how light stimulates circadian and other 'non-visual' responses (Lockley 2008, In Press) (Veitch and others 2004), although these factors are beyond the scope of the current paper and are the basis for future applications.

The human circadian rhythm has an internal period of between 23.524.7h, with an average of 24.2h among healthy adults (Czeisler and others 1999) and therefore needs to be reset to exactly 24 hours each day in order to maintain an appropriate phase relationship with the environment. Light is the most powerful environmental entraining stimulus and daily ocular exposure to a 24-hour light-dark cycle is required to reset the internal pacemaker to 24 hours. Most totally blind people, who do not receive daily light information via the eyes, are unable to synchronize their internal clocks to 24 hours and consequently suffer from 'non-24-hour sleep wake disorder' in which sleep and other daily rhythms run on patients' own internal clock time (Lockley and others 1997) (Lockley and others 1999). Similar entrainment disorders are caused by shift-work and during jet-lag, when the environmental light-dark cycle becomes desynchronized from the internal circadian clock time. 
Depending on the timing of light exposure, light can both phase advance the clock to an earlier time or phase delay it to a later time; the magnitude of the phase shift depends on the intensity, duration and number of exposures. The direction and magnitude of phase shifts induced by a stimulus are defined by a Phase Response Curve (PRC) and under normal conditions. Light exposure in the later day/early night causes a phase delay of the pacemaker whereas light exposure in the late night/early day will phase advance the clock (Lockley 2008, In Press). Light exposure during the middle of the day has less of a phase resetting effect on the circadian system (Lockley 2008, In Press) (Veitch and others 2004) but remains important for internal monitoring of day- and night-length in relation to seasonal changes in light exposure (Wehr 2001). Light exposure during the day also acutely improves alertness (Phipps-Nelson and others 2003) (Ruger and others 2006) (Vandewalle 2006) as it does during the night (Cajochen and others 2000). At night, the circadian system is highly sensitive to light exposure with 100 lux white light initiating $50 \%$ of the maximal response to as much as 1,000-10,000 lux exposure (Cahochen and others 2000) (Zeitzer and others 2000) (Zeitzer and others 2005) (Ruger and others 2005).

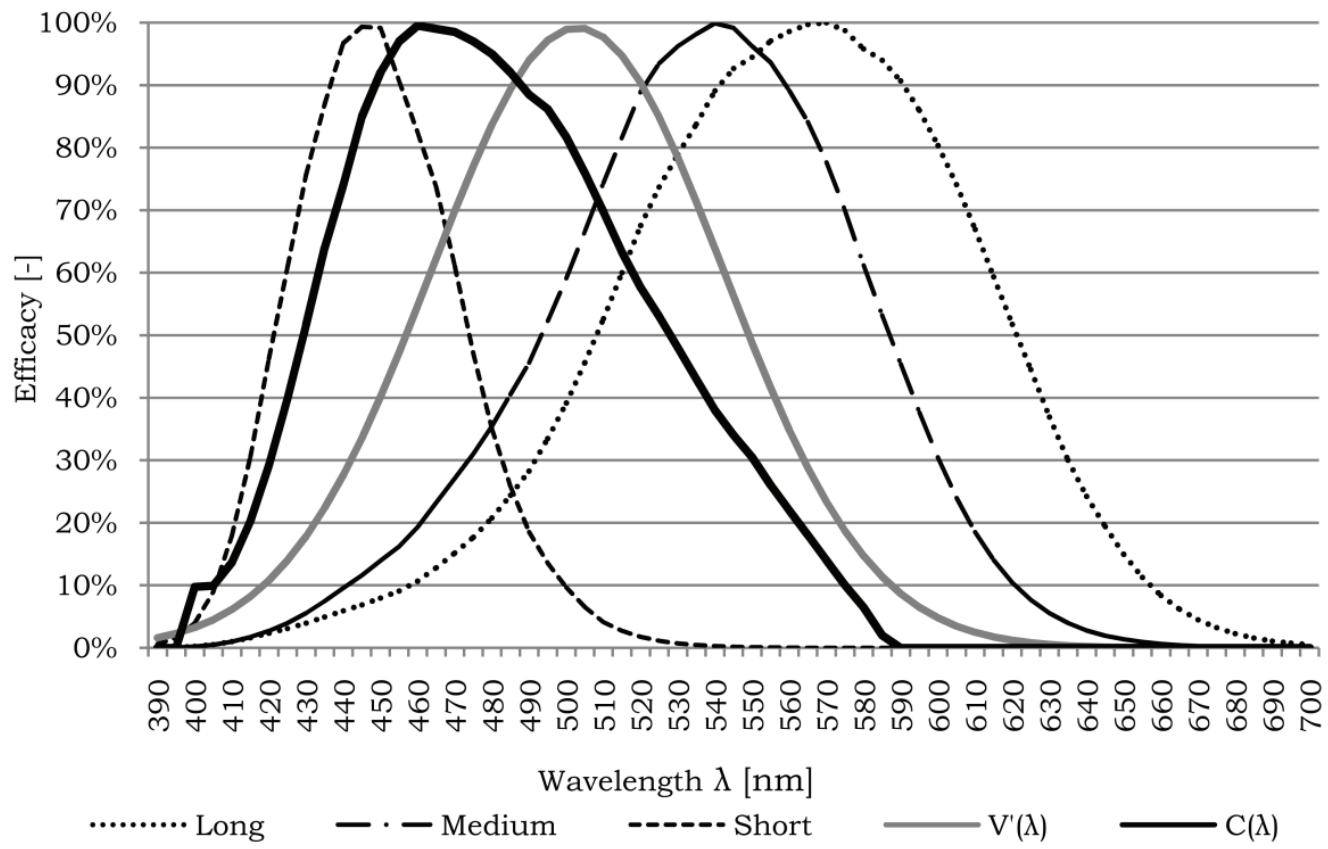

Fig. 1. Spectral Responses of Photopic Long (Red), Medium (Green) and Short (Blue) Opsins (Sharpe and others 2005), Scotopic V'(A) (CIE 1924), and Melanopsin $\mathbf{C}(\boldsymbol{\lambda})$ Systems (Philips Lighting).

The direct alerting effects of light are of particular interest for lighting design applications. Light exposure at night simultaneously suppresses melatonin production, the hormone which acts as the biochemical marker of night in both diurnal and nocturnal animals. In humans, melatonin onset is closely associated with the onset of the circadian rhythm of sleepiness and, if given synthetically, induces sleepiness. These findings suggest that the alerting effects of light at 
night may be due to the simultaneous suppression of melatonin production. This is not the case for the alerting effects of day-time light exposure, however, as no melatonin is produced during the day. It is possible that there are multiple mechanisms by which light can improve alertness and performance (Lockley and Gooley 2006) and these mechanisms are the subject of ongoing research (Phipps-Nelson and others 2003). For practical purposes, until more data are available, we have considered that the alerting process mirrors that by which melatonin is suppressed. The dose-response is similar to that for melatonin suppression for night-time light exposure (Cajochen and others 2000) (Zeitzer and others 2000) and the alerting aspects of light are similarly blue-shifted relative to scotopic and photopic vision as for melatonin suppression (Cahochen and others 2005) (Lockley and others 2006).

This paper will build upon specific biological findings to propose methods by which circadian illumination may be considered in building design. From the literature, it appears that there are approximately five critical aspects to circadian rhythm: intensity, timing, duration/pattern, photic history, and spectrum (Lockley 2008, In Press) (Veitch and others 2004). The timing and spectral requirements for circadian illumination differ enough from other forms of illumination, such general and task illumination, to warrant consideration of their impact upon lighting design.

The objective of this paper is to describe the characteristics of (day)light that may promote human health by providing lighting for the appropriate synchronization of circadian rhythms, and to use these findings to make specific (day)lighting recommendations, grounded in biological findings. Specific metrics and findings will be discussed but it is the relative evaluation and improvement in circadian efficacy which is of concern. In other words, these findings should not be taken as an absolute measure of circadian efficacy or health potential because the precise definition of the human circadian action spectrum $\mathrm{C}(\lambda)$ is still underway. For example, debate exists as to the extent of the contribution of rods and cones in addition to melanopsin, or whether non-visual photoreception exhibits spectral opponency, as demonstrated for vision. Similarly, there may be timeof-day differences in the spectral sensitivity function, effects of prior photic history or inter-individual or inter-population differences that may have to be taken in to account in applying these findings. Therefore, while we use a nominal definition of $C(\lambda)$ in the current analyses, the findings of this paper are not specifically dependent on the curve presented, or any curve, and thus a consensus curve may be substituted into the process described here as knowledge advances. These data represent a starting point from which we can begin to address more practical and flexible solutions as needs inevitably arise.

\section{METHOD}


In a retrospective analysis of a lighted space, it is relatively simple to measure the spectral distribution of light received at a given sensor point across a specific wavelength range so as to draw conclusions about the source's efficacy - typically based on the human eye's photopic response $\mathrm{V}(\lambda)$. This concept can also be extended to calculating simultaneously a "circadian efficacy" based on $C(\lambda)$ thereby providing additional information about the quality of the light exposure. Prospectively, the problem is quite different. Widely available simulation tools have limited or non-existent spectral simulation capabilities, and those simulation capabilities that exist are based on the photopic visual response, and do not provide radiometric spectra from which a circadian response could be deduced. To fill this gap, a methodology is proposed by which reasonable assertions of circadian efficacy can be made.

The process proposed here starts with calculation of the relative circadian efficacy of light sources with known spectra. Spectral information can be difficult to obtain, and following design, there is little certainty that a lamp with a specific spectrum will be installed and maintained over the life of a building (SLA 2007). So, this paper relies upon standard CIE illuminants including illuminants A, F2, F7, F11, E, D55, D65 and D75 (CIE 2006) (ASTM International 2006). Spectra for $4100 \mathrm{~K}$ and $18000 \mathrm{~K}$ lamps manufactured by Philips Lighting (Mills and others 2007) and 460nm and 555nm $( \pm 10 \mathrm{~nm}$ halfpeak bandwidth) monochromatic exposures (Lockley and others 2003) (Lockley and others 2006) are also considered. The use of CIE illuminants allows for general conclusions that are not sourcespecific, but instead broadly apply to commercially available lamps with similar characteristics. In the spectral analysis process that follows, these radiometric spectra are analyzed for their shortwavelength component content, from which a relative circadian weighting is derived. This process, when compared across a wide variety of illuminants, ultimately produces a chart (Fig. 4) which can be used to quickly reference the circadian potential of a considered light source in a temporally neutral application.

\subsection{EVALUATION OF CIRCADIAN EFFICACY}

The spectral analysis process scales a known (or presumed) relative radiometric spectrum [unit-less], which is modified to provide photon density [Photons $\left./ \mathrm{cm}^{2} \mathrm{~s}^{-1}\right]$, irradiance $\left[\mu \mathrm{W} / \mathrm{cm}^{2}\right]$, and circadian stimulus $[\mathrm{W}-\mathrm{C}(\lambda)]$. Photometric values (e.g. lumens) are the result of integrating a radiometric spectrum over the visible range, after having weighed it by a known response curve, $V(\lambda)$, as expressed in Eq. 1:

$$
\varphi \text { photo }(\mathrm{lm})=683 \int_{\sum_{\lambda=500 \mathrm{~mm}}^{\mathrm{annmm}}}^{\mathrm{N}} \mathrm{V}(\lambda) * \varphi_{\text {radio }}(\lambda) \mathrm{d} \lambda
$$

The process described here inverts this. We will assume a relative radiometric spectrum based on standard illuminants and use simulations below in a non-spectral manner to arrive at illuminance 
[lux]. The relationship between illuminance and radiometric spectrum is indeed precise (enough) that a known illuminance [lux] can be used to transform a known relative (unit-less) radiometric spectrum into an absolute spectral power distribution in Watts. This process begins by finding the unit-less photometric response from a normalized radiometric spectrum, in $5 \mathrm{~nm}$ increments, by multiplying the radiometric spectrum by $683[\mathrm{~lm} / \mathrm{W}]$ and $\mathrm{V}(\lambda)$ (Sharpe and others 2005). The calculated ratio of the total photometric response to each instance $(\Delta 5 \mathrm{~nm})$ serves as a scalar factor. The actual illuminance at each $5 \mathrm{~nm}$ increment is then the product of this scalar factor and the total illuminance [lux]. The same scalar factor can be used to convert the normalized radiometric spectrum to power, in Watts (over the wavelength range considered only). Since the original input for this computation process was lux $\left[1 \mathrm{~m} / \mathrm{m}^{2}\right]$, calculation of irradiance $\left[\mu \mathrm{W} / \mathrm{cm}^{2}\right]$ is then trivial. Photon density, which is another measure of radiometric power, can be calculated from the radiometric data using wavelength, a scalar factor, Plank's constant, and the speed of light.

Circadian stimulus, on the other hand, has no agreed upon measure. For the purposes of this paper, the radiometric spectrum [W] is simply multiplied by the $\mathrm{C}(\lambda)$ curve to give a circadian weighted value in watts $[\mathrm{W}-\mathrm{C}(\lambda)]$. An experimental circadian efficacy curve, $\mathrm{C}(\lambda)$, developed by Philips Lighting, based on data from Brainard and others 2001 and Thapan and others 2001, has been used in the current analysis but other predictions of $C(\lambda)$ may equally apply. An overview of this process in the form of equations is provided in the Appendix of this document.

This use of illuminance to infer radiometric properties has been validated in two cases. First, by comparison to published data for $460 \mathrm{~nm}$ and 555nm monochromatic light sources (Lockley and others 2003) as demonstrated in Table 1 and second, by comparison to experimental data gathered by Zeitzer and others (2000) (Zeitzer and others 2000) (Fig. 2). The calculated correlation in the latter case is 0.99, indicating a strong linear relationship between the measured and inferred data.

\begin{tabular}{|c|c|c|c|}
\hline & Photons $/ \mathrm{cm}^{2} \mathrm{~s}^{-1}$ & $\mu \mathrm{W} / \mathrm{cm}^{2}$ & Photopic Lux \\
\hline 460nm measured & $2.8 \times 10^{13}$ & 12.1 & 5.0 \\
\hline 460nm inferred & $2.8 \times 10^{13}$ & 12.11 & 8.13 \\
\hline $555 \mathrm{~nm}$ measured & $2.8 \times 10^{13}$ & 10.0 & 68.1 \\
\hline $555 \mathrm{~nm}$ inferred & $2.8 \times 10^{13}$ & 10.02 & 67.7 \\
\hline
\end{tabular}

Table 1. Comparison of Inferred and Measured (Lockley and others 2003) Radiometric Values of Two Monochromatic Sources 


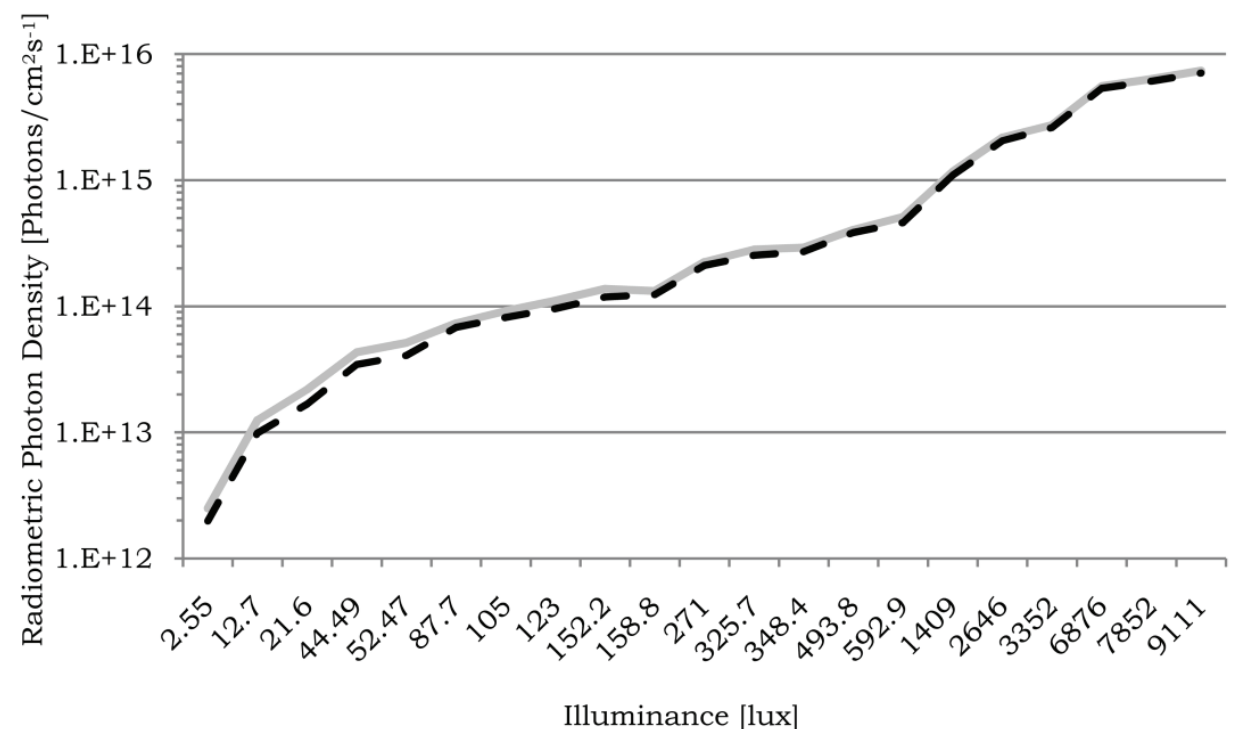

Fig. 2. Comparison of Calculated (Dashed) and Measured (Gray, Solid) (Zeitzer and others 2000) Photon Density of 4100K Lamp at Specified Illuminance Values

Since the circadian efficacy of a light source is partly based on a spectrally weighted intensity of light, it is critical to the process that follows to establish a reasonable daylight illumination goal. For daylight, the spectral properties of the light change based on weather and window properties. Additionally, variability due to time, season, and weather make the prediction of daylight illuminance at a specific point somewhat uncertain. These are addressed in two ways: by the use of annual daylight estimation tool that takes into account weather and sky conditions and by setting an appropriate spectrallyweighted illumination goal based on the predominant illuminant considered (D55, D65, D75).

Daylight Autonomy, which estimates the probability of achieving a target daylight illuminance level (Reinhart \& Walkenhorst 2001), takes these into account using US Department of Energy weather files and the Perez Sky Model (Perez and others 1993). Daylight Autonomy may be calculated using the RADIANCE-based DAYSIM simulation program, both of which have been extensively and successfully validated for daylighting calculations (Reinhart \& Walkenhorst 2001). ECOTECT is the modeling interface from which the DAYSIM program is launched. In DAYSIM, material properties such as reflectance and specularity are adjusted to recommended values (Reinhart 2006). Similarly, the rendering properties used by the RADIANCE-based engine are set according to recommendations (Reinhart 2006). The program outputs include Daylight Autonomy [\%] and an annual illuminance file (ILL). Daylight Autonomy is used in a straightforward manner as described below. For the annual illuminance data, a MATLAB-based script was used to generate temporal maps which show the timing and intensity of daylight with respect to a fixed position (Kleindienst and others 2008). 
Daylight's spectrum is constantly changing based on time, orientation of the viewer, and window properties. The north sky on a clear day, for example, is significantly bluer than morning sunrise. To account for this variability, D65 (ASTM International 2006) is assumed for south orientations, while D75 (ASTM International 2006) is assumed for north orientations. For east and west orientations, D65 is assumed with some qualifiers. For example, D65 will over-report blue light contribution during direct exposure (compared to D55 (ASTM International 2006)), and will underreport blue light contribution during indirect exposures. As far as windows are concerned, the filtering effect of glass is expressed by the product of the source spectrum, $S(\lambda)$, and the transmittance spectrum, $\tau(\lambda)$ (Lawrence Berkeley National Laboratory).

For artificial illumination, annual daylight estimation is replaced by a simple lighting simulation in RELUX. The artificial lighting simulation program RELUX is also RADIANCE-based and has been validated for use in architectural lighting applications (Christakou \& Amorim 2005). For electric luminaires, the spectrum does not materially change based on weather or timing for most commercially available systems, so no additional adjustments are made to compensate for these.

In addition to spectrum and illuminance, the photobiology literature also emphasizes timing, duration, and contrast-here simplified as "timing." In a hospital room, the patient is assumed to be stationary. This allows for the evaluation of daylight in one location. For the purposes of calculating DA, a 12-h day (06:00-18:00) is assumed as the average daylit period. The temporal mapping that follows is used for a more detailed analysis of lighting conditions over time. Temporal Maps, derived from DAYSIM output files, display the shifting peak illuminance of daylight, accounting for weather, season, and orientation. The test cases presented will have obvious daylight timing effects-east-facing rooms will experience bright light in the morning, while those facing west will experience it in the evening. The point of this method is to predict peak illuminance in more complex, real-world circumstances. As artificial light sources have simple on-off controls, they are assumed to be temporally neutral for the purposes of the method described in this paper.

The process by which reasonable assertions of the circadian efficacy of an architectural design may be made is documented in Fig. 3. This paper aims to synthesize the spectral and intensity aspects of light, as shown on Fig. 3, into a common reference (Fig. 4). So, an architectural design would start with enough information (i.e. weather data, location) and detail (rooms, windows, massing) to build a reasonable DAYSIM model. Through a non-spectral simulation, the probability of achieving the daylight illuminance threshold is evaluated. Additionally, temporal mapping allows for comparison to timing goals. The feedback action allows for refinement of the design. This process reuses some of the terminology found in a previously 
published two-way approach to daylighting simulation (Mahdavi and Berberidou-Kallivoka1993). Furthermore, daylighting is not the only demand placed on a proposed design. An optimizer, featured in Fig. 3 , is thus recommended to refine the subject space's properties accounting for other criteria such as comfort and energy efficiency.

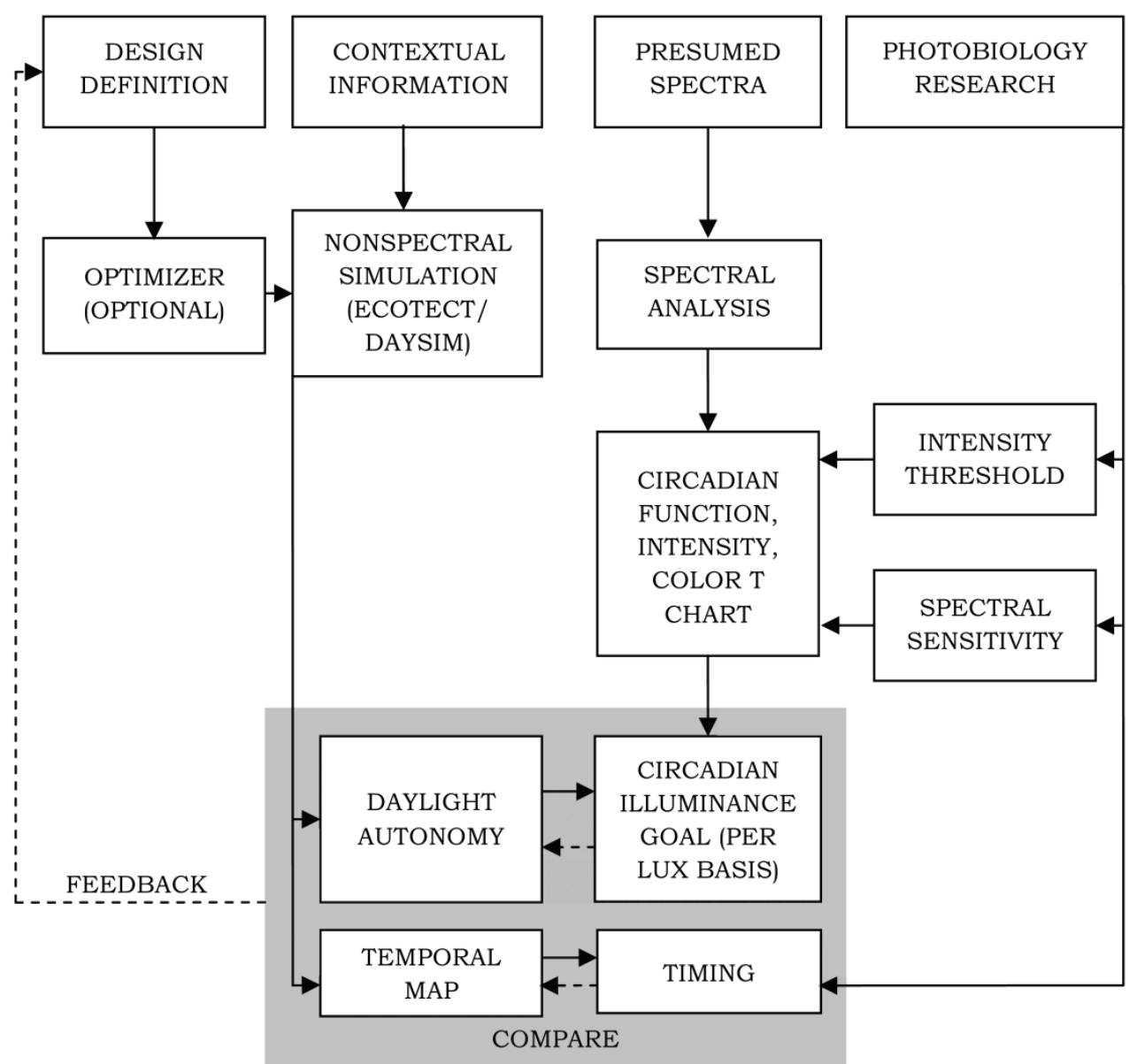

Fig. 3. Circadian Efficacy Evaluation Process (Pechacek, Andersen, \& Lockley, 2008)

\subsection{COMPARISON OF ILLUMINANTS}

Using the above techniques, the $\sim 300$ lux vertical illuminance from the benchmark studies is translated into $100 \%$ circadian stimulus (Cajochen and others 2000) (Zeitzer and others 2000) with a calculated circadian power of $0.27 \mathrm{~W}-\mathrm{C}(\lambda)$. A comparative study was then undertaken among artificial light sources and daylight sources to compare their relative circadian efficacy. This dataset was finally plotted on a graph whose design was inspired by the ASHRAE Psychometric Chart (Fig. 4).

As suggested by this chart, daylight (D55, D65, D75) outperforms the artificial light sources considerably. This difference may be attributed 
to daylight's spectral peak $(530 \mathrm{~nm}$ in the morning, 460nm at noon, and $450 \mathrm{~nm}$ for overcast days) which closely correlates to the peak action spectra of the circadian system $\left(\lambda_{\max } \approx 480 \mathrm{~nm}\right)$ for much of the day (Lockley 2008, In Press). As shown on the chart, the daylight target illuminances for the analysis that follows are 210, 190, and 180 lux for morning/evening (D55), noon (D65), and overcast (D75), respectively. For the range D55 to D75, this suggests an uncertainty of \pm 10 -20 lux. The target illumination for artificial lighting is 360 lux for an F2 lamp or 228 lux for an F7 lamp.

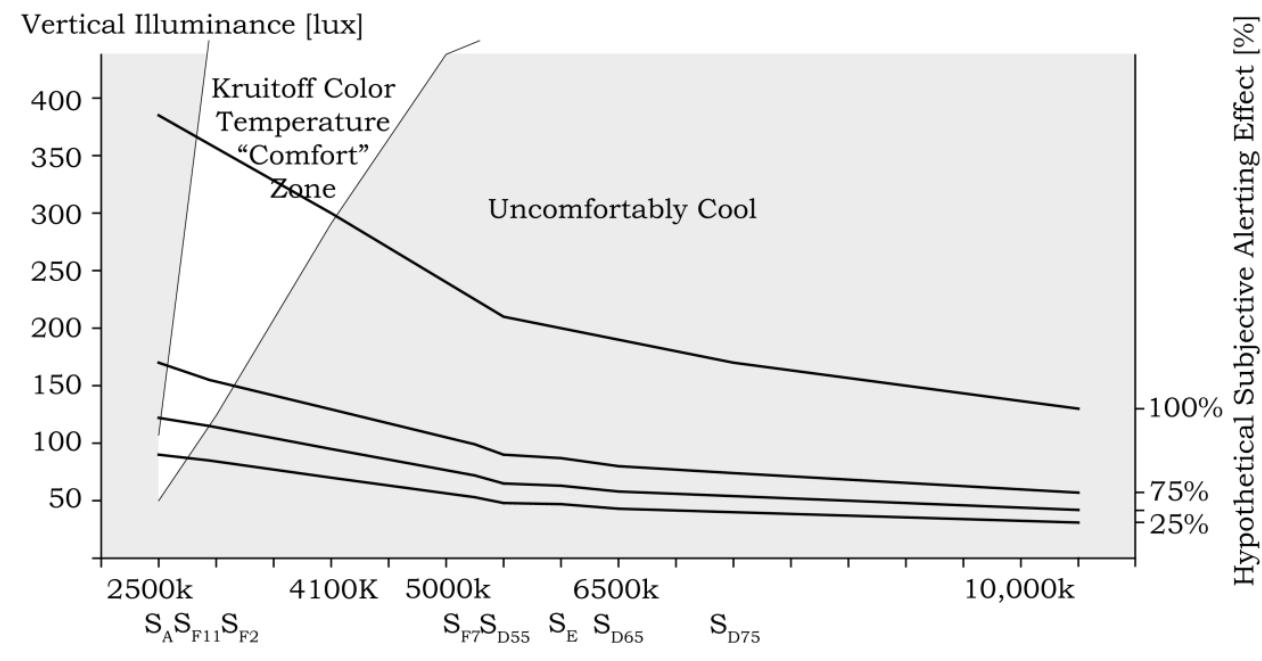

Approximate Source Color Temperature $[\mathrm{K}]$

Fig. 4. Alertness Benefit (Cajochen and others 2000) from Illuminants by Color Temperature: Comparison of Various Light Sources (ASTM International 2006) (CIE 2006) by Color Temperature, Illuminance, Comfort, and Circadian Efficacy assuming Spectral Neutrality of Construction Materials and Biological Temporal Neutrality.

\section{APPLICATION EXPERIMENTS ON A HOSPITAL PATIENT ROOM}

An imaginary patient room located in Boston, USA was considered as a case study. The room dimensions were established based on information published by the AIA and the US Department of Defense (American Institute of Architects 2006). A Hill-rom Versa Care bed system measures 40" [1016mm] wide, 94.5" 2400mm] deep, and 37" [940mm] high, and its location is shown in Fig. 5. To best account for clearances and accessibility requirements, a room of 16'-0"W by 13'0"D [4877 $\mathrm{mm}$ by $3962 \mathrm{~mm}$ ] is used in this study. Each patient room is required to have an adjacent toilet/shower room (American Institute of Architects, 2006). In this study, the toilet is placed on the corridor-side of the patient room rather than on the façade for daylighting purposes. The target point chosen for analysis is shown on Fig. 5, 4'-0" [1219mm] above the finished floor. 


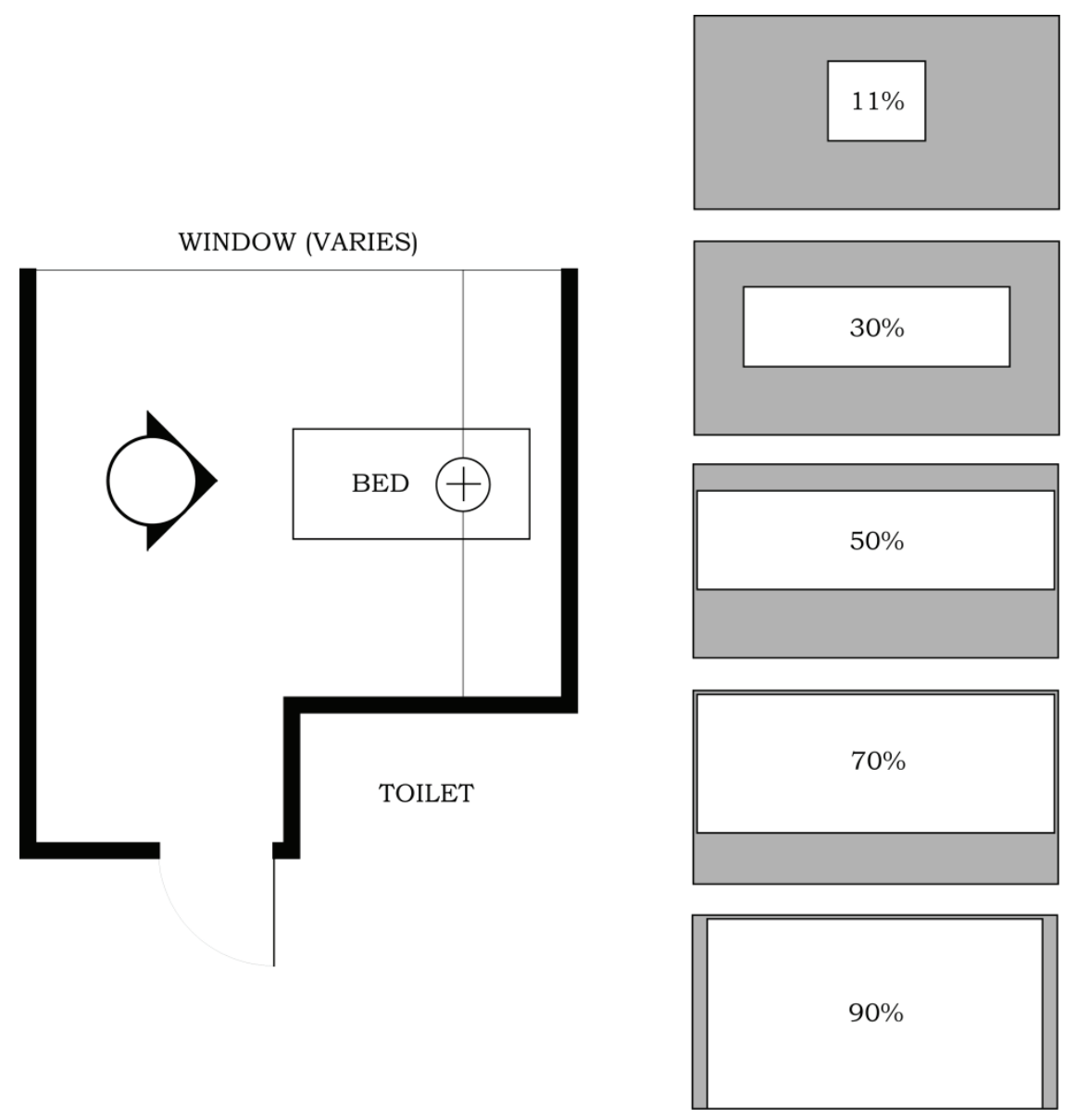

Fig. 5. L: Hospital Patient Room Configuration. Test Point is Noted by "+" and Vertical Illuminance Test Plane by a Gray Line as Viewed from the Elevation Marker at the Foot of the Bed. R: Test Window Configurations by Glazing Factor (\%).

The room was assumed to be oriented due north, south, east, or west to demonstrate how changes in orientation affect achievement of DA goal. Glazing fractions of $11 \%, 30 \%, 50 \%, 70 \%$, and $90 \%$ were also chosen to demonstrate how changes in window size further affect interior illumination levels (Hausladen and others 2005) (Fig. 5). Spectral data for glazing material was obtained from the Optic 5 program (LBNL) and Pilkington 6mm [approx. 1/4"] glass was chosen for this experiment because of wide product availability, and because the $6 \mathrm{~mm}$ glass closely approximates the $1 / 4$ " glass commonly used in the United States for commercial construction. Windows were assumed to be double pane with a clear, Low-E outboard pane.

For most of the following experiments, the interior surfaces of this room were assumed to be spectrally neutral. The simulation parameters and material properties follow recommendations provided in Reinhart (2006): gypsum board walls $60 \%$ reflective, vinyl floors $30 \%$ reflective with 0.05 specularity, acoustical ceiling tiles $80 \%$ 
reflective with a specularity of 0.01 (Reinhart 2006). The window transmissivity $\left(\tau_{n}\right)$ was modeled at $74.3 \%$ (LBNL 2003).

\subsection{EXPERIMENT 1 - ELECTRIC ILLUMINATION}

Much of the literature regarding photobiology and lighting has focused on artificial lighting sources. The use of artificial lighting is pervasive, and perhaps inescapable, especially in tightly controlled environments such as operating rooms. Experiment 1 hypothesizes that artificial lighting standards for hospital patient rooms are inadequate to meet the circadian illumination requirements of a patient.

A general purpose troffer fixture was modeled. Dimensions were modified to 2'-0" by 4'-0" [610mmx1219mm]. System power was set at $64 \mathrm{~W}, 96 \mathrm{~W}$, or $128 \mathrm{~W}$, depending on the lamp configuration tested. The total luminous flux was specified at $57001 \mathrm{~m}, 85501 \mathrm{~m}$, or $11,4001 \mathrm{~m}$, depending on lamp configuration. The luminaire was positioned 6'-8" [2032mm] (on center) from the adjacent window wall, and 12'-0" [3658mm] from the wall opposite the bed. The mounting height was set equal to the ceiling height of the room 8'-6" [2591mm] above the finished floor. The test plane was 4'-0" [1219mm] above finished floor, set at the approximate height of the patient's head. A vertical test plane located at the approximate location of the patient's head was also used-reference Fig. 5 for positioning. For the purposes of this model, no over-bed fixture was simulated because they are used for reading or examination, not for general room illumination.

The results of a 2-lamp configuration in the light fixture simulated are provided in Fig. 6. The peak horizontal illumination is 495 lux, with values of 300 lux occurring approximately where a patient's head would be positioned. When the same illumination is measured vertically, the illumination level is about 100 lux. These values comply with illumination recommendations in the IESNA manual for healthcare facilities, which require 30-300lux in this application, depending on task (IESNA 2006). While complying with national standards for general illumination purposes, this room does not meet the circadian illumination goal (360 lux, vertical, for F2 lamp or 228 lux, vertical, for F7 lamp). 

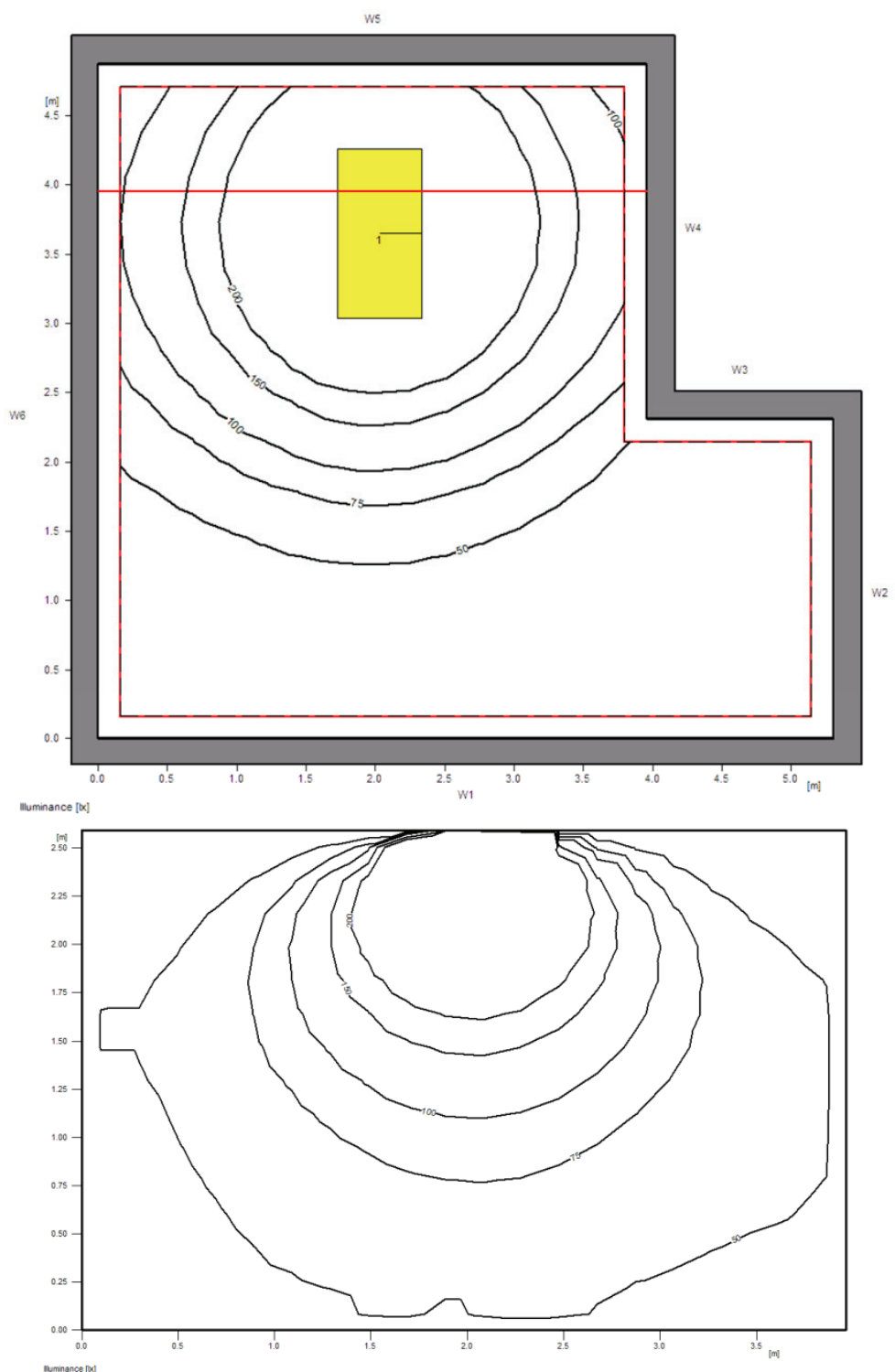

Fig. 6. Artificial Horizontal (T) and Vertical (B) Illumination Levels from a 2-Lamp Fixture in Subject Patient Room

In the case of the cool white lamp (F2), the simulated vertical illumination level falls between $25-50 \%$ of the desired circadian efficiency. For the daylight lamp (F7), the range is $50-75 \%$. As shown in Fig. 4 above, the use of higher color temperature lamps (i.e. F7) will yield improved circadian stimulus, however, as the comfort line indicates, a higher illumination may be necessary for subjective occupant comfort. Additionally, typical artificial illumination sources are temporally neutral-meaning that the timing aspect of the illumination does not correspond to social or environmental circadian organization. Lacking this critical third element of circadian stimulus, artificial illuminants are best used for general illumination purposes, and not for circadian illumination, especially as windows are required in hospital patient rooms and better perform as circadian illuminators (Experiment 2). 


\subsection{EXPERIMENT 2 - IMPACT OF GLAZING FRACTION AND ORIENTATION ON DAYLIGHT AUTONOMY}

A set of Daylight Autonomy calculations were performed to evaluate how effectively natural light reaches an imaginary patient in a hospital bed. In this case, DA is used spatially and temporally with respect to illumination and design options. Daylight Autonomy, expressed as a percent (\%) at a target point (i.e. the patient's head location), gives a probabilistic rating of achieving the circadian illumination goal and can be used to compare design options (Fig. 7). The circadian efficacy of daylight is calculated using an equivalence chart, so the target illuminance is weighted for spectral composition. Daylight Autonomy as expressed in a plane shows the spatial dimension within one design variation. Temporal mapping of illuminance at one point gives time and illuminance information, but does not provide spatial data. The confluence of these three approaches provides an objective assessment of the circadian potential of the space through simulation.

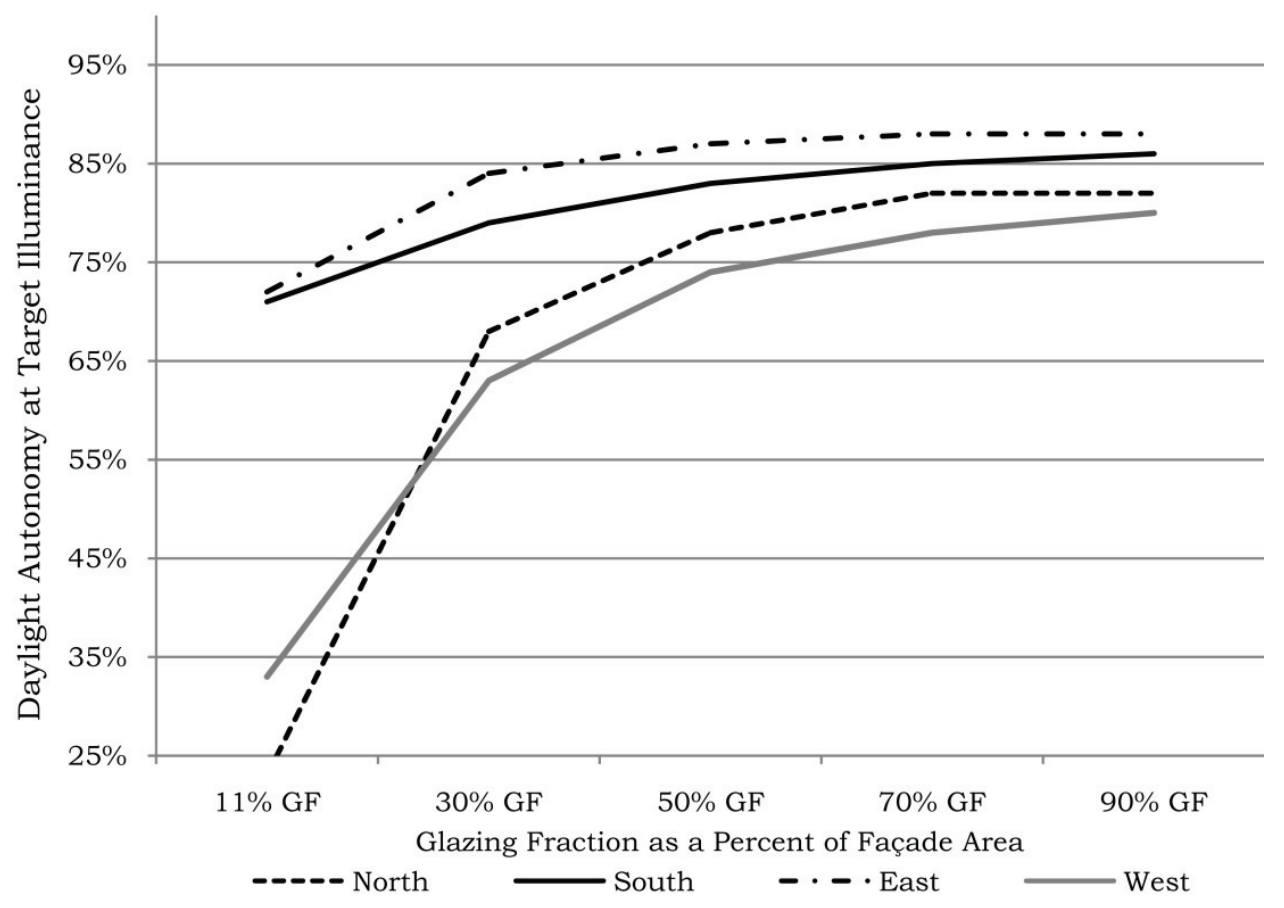

Fig. 7. DA (\%) at the patient's head (assessed on a vertical plane) at Test Point (190 lux or 180 lux (north), 06:00-18:00h) by Glazing Fraction (\%) for North, South, East, and West Facing Hospital Rooms in Boston, USA. (Pechacek, Andersen, \& Lockley, 2008)

Figure 7 documents how varying room orientation and glazing fraction affects its circadian potential compared to the spectrallyweighted illumination goal. In each case, the room was merely rotated to the test orientation, not mirrored, so differences in the east and west orientations are exaggerated by the effects of cutoff angles created by the window and room geometry. North and west façades 
at $11 \%$ glazing fraction achieve the circadian-weighted daylight illumination goal less than $35 \%$ of the time in Boston. Additionally, these results suggest a point of diminishing return at around $50 \%$ glazing fraction for all orientations. While these results are compelling, they represent only a partial analysis because they do not consider the temporal or spatial distribution of daylight.

The realization of target DA spatially is described in Fig. 8. These diagrams display DA at 190 lux (180 lux North) in a vertical plane located approximately at the target location (Fig. 5), perpendicular to the window. A vertical illuminance test plane is used to represent the natural forward looking gaze of a hospital patient. The window is located to the left in each diagram. The results of this analysis indicate that achievement of the DA goal varies by $20 \%$ or more based on location in the same room. This information can be used by a designer to modify patient position and/or window configuration to make the best use of the daylight available. For example, in the north-facing room, the DA diminishes quickly with distance from the window. In contrast, the east facing window displays strong penetration of daylight into the general location of the patient bed as demonstrated by the diagonal orange-yellow streak from the left (window) to the center of the diagram.
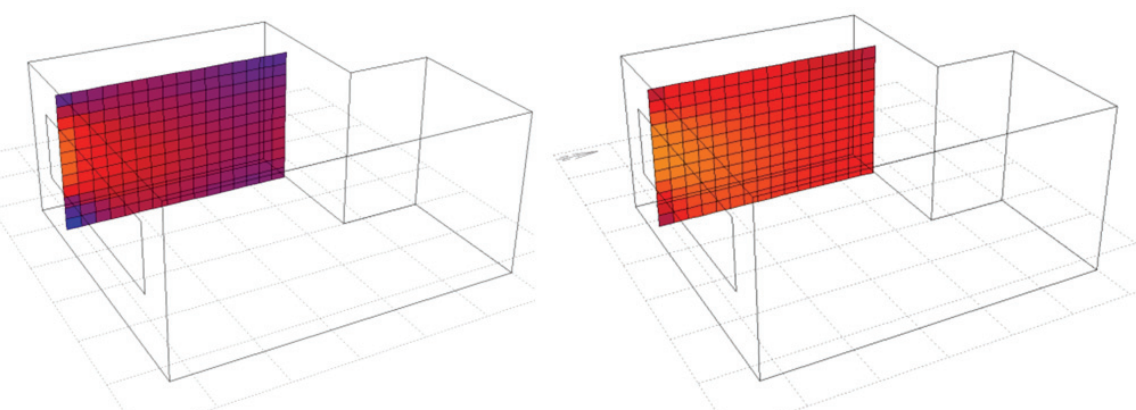

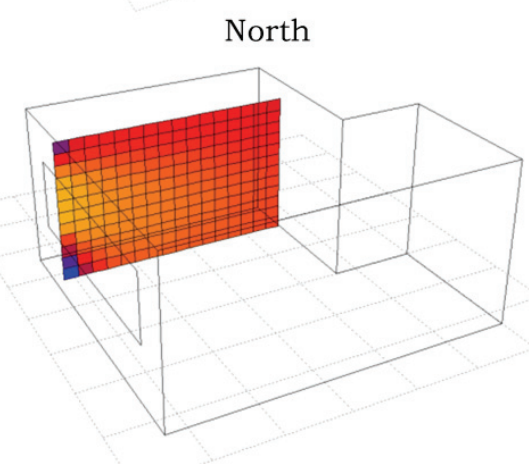

East

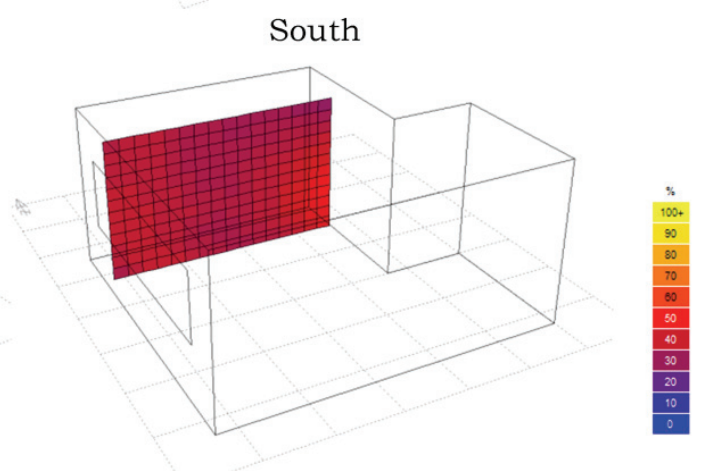

West

Fig. 8. Effects of Orientation on Daylight Autonomy Goals for Patient Room, GF $=30$ percent, no shades. Location: Boston, USA. (Pechacek, Andersen, \& Lockley 2008). 
Figure 9 demonstrates brightness of daylight at the patient's eye in 5 minute increments for a typical year in Boston. This diagram was derived from output created by DAYSIM (ILL file) (Kleindienst and others 2008). The result indicates the range of times when sunlight will be brightest in the subject space. As timing is a critical factor in effective circadian design, diagrams such as these provide helpful validation of daylight exposure timing. From the data presented in Fig. 9, it is clear that an east-facing room performs best in providing intense light in the morning. In contrast, the west-facing window provides intense illumination in the evening. These results may seem obvious for a room with simple geometry and orientation, however more complex spaces with multiple exposures may benefit from this type of analysis.
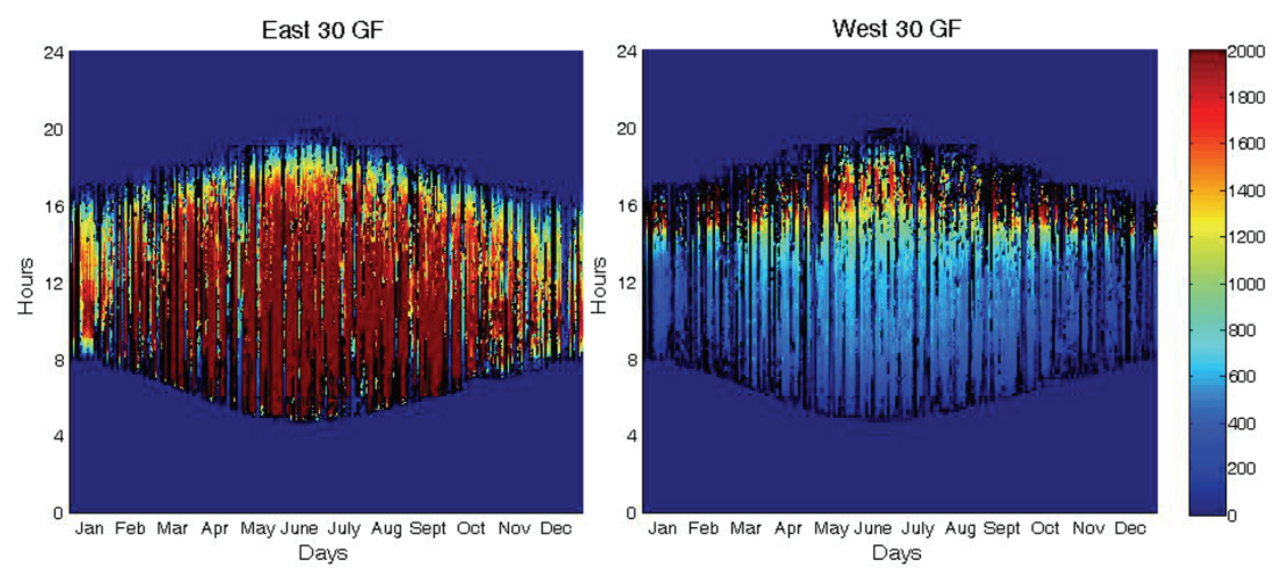

Fig. 9. Temporal Maps of East (L) and West (R) Facing Patient Room, GF $=30 \%$, Max Illumin $=2000$ lux, Min Illumin. $=0$ lux. No Shading

Device or Blinds Specified. Vertical axis: time ( $0 \mathrm{~h}$, bottom to $24 \mathrm{~h}$, top). Horizontal axis: day/month of year (Jan, L. to Dec, R.). Location: Boston, USA.

The effect of shading devices and blinds on circadian-stimulating illumination levels spatially is shown in Fig. 10. As shown in the diagram on the top left, a south facing window with $30 \%$ glazing fraction, can expect to achieve the target illumination level during most of the year around noontime. When a simple shading device system of horizontal louvers (Fig. 10, top right) is added to the outside of the window, the probability of achieving this illumination is reduced. The reduction in peak illumination is exaggerated by a passive venetian blind user as shown in Fig. 10 (bottom). In these cases, the result of using venetian blinds is a significant reduction in circadian effectiveness of the space by overly reducing the intensity of the available daylight to below the target level of 190-180lux. This is significant because the use of venetian blinds in this manner is a likely representation of human behavior. 


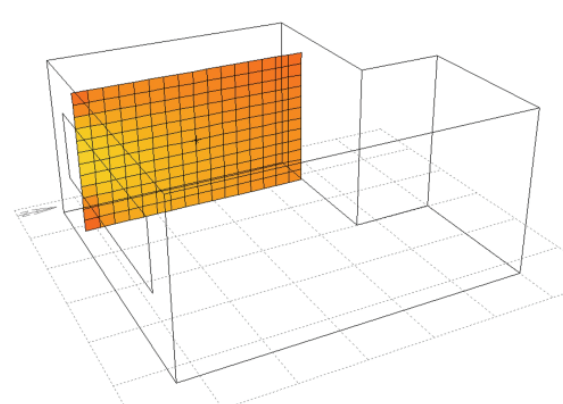

No External Shades or Internal Blinds

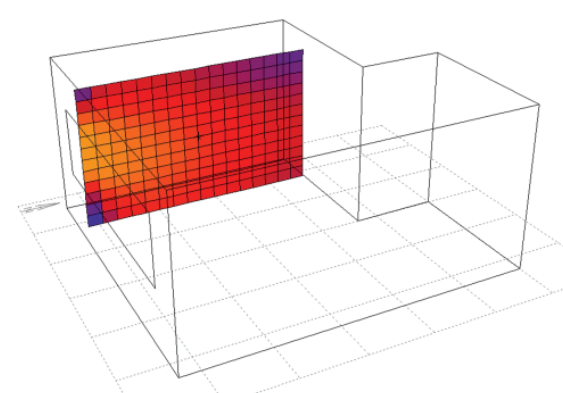

Internal Blinds Only

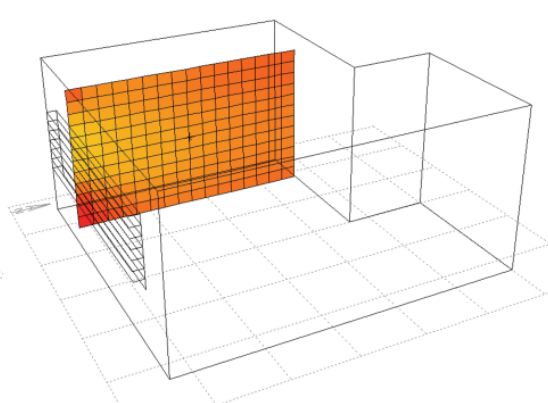

External Shades, No Internal Blinds

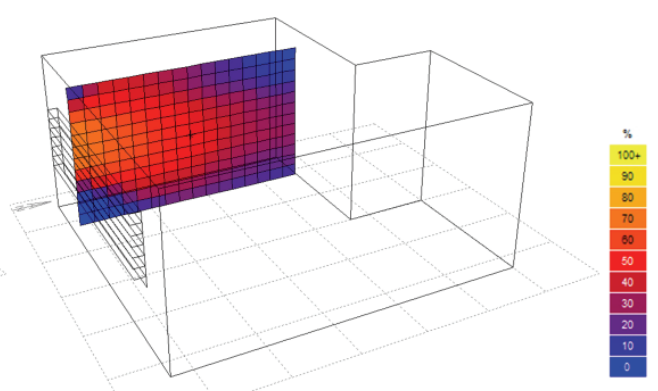

External Shades and Internal Blinds

Fig. 10. Effects of Window Blind Use on Daylight Autonomy Goals for South Facing Patient Room, GF=30\%, Shading Device (Right), Blinds (Bottom). Blinds for Passive User. Location: Boston, USA

\subsection{EXPERIMENT 3 - SPECTRAL NEUTRALITY}

One of the central assumptions of this paper is the spectral neutrality of the space considered. Built spaces are rarely spectrally neutral, however. A simple experiment was therefore executed, hypothesizing that the spectrum of light received at the eye would be the weighted sum of the direct sky component's spectrum (which would be a function of $S(\lambda) \tau(\lambda)$ ) and the internally reflected component's spectrum (which would be a function of $S(\lambda) \tau(\lambda) \rho_{\mathrm{fw}} \rho_{\mathrm{cw}}(\lambda)$ ); no external obstructions were considered for simplification reasons. The purpose of this experiment was to validate the assumption of spectral neutrality using RADIANCE.

Similar to Wandachowicz (2006), the spectrum studied is divided into three components $(\Delta \lambda=5 \mathrm{~nm})$ : Blue $380-495 \mathrm{~nm}$, Green $500-625 \mathrm{~nm}$, and Red 630-780nm. The source spectrum $\mathrm{S}(\lambda)$ (ASTM International 2006) and transmission spectrum $\tau(\lambda)$ (LBNL), were summed over their respective ranges and normalized. One key difference in the present paper is the use of radiometric, not photometric, spectra. Used in this manner, RADIANCE is a 3-channel ray tracer which predicts the relative decay in the component channels following reflections. It is this relative decay which is precisely of interest in this experiment. 
For the purposes of this experiment, a south facing room with $30 \%$ glazing fraction was simulated in RADIANCE. A CIE overcast sky with $\mathrm{D} 75$ spectral properties was set $(R=0.80, G=1.0, B=1.04)$. Simple RGB values (Table 2) were interpolated based on Wandachowicz (2006) to estimate the reflectance spectra $\rho(\lambda)$ of painted walls (Wandachowics 2006). The RAL 9003 paint color, in this case, is an approximation of an essentially neutral source. See the Appendix for source, transmission, floor, and ceiling RADIANCE values.

\begin{tabular}{|l|l|l|l|}
\hline & $\mathrm{R}_{630-780 \mathrm{~nm}}$ & $\mathrm{G}_{500-625 \mathrm{~nm}}$ & $\mathrm{~B}_{380-495}$ \\
\hline RAL 9003 & 0.98 & 0.86 & 0.85 \\
\hline DuPont Color 72 & 0.79 & 0.50 & 0.02 \\
\hline DuPont Color 28 & 0.26 & 0.41 & 0.52 \\
\hline RAL Color 1015 & 0.78 & 0.69 & 0.51 \\
\hline
\end{tabular}

Table 2. Normalized Radiometric Spectral Reflectance $(\rho(\lambda))$ Approximations used in RADIANCE RGB Simulations

The results of this RADIANCE experiment demonstrate that for spectrally neutral spaces, the spectrum of the light source $S(\lambda) \tau(\lambda)$, shown in gray, is not materially altered (Fig. 11, Top). On the other hand, walls painted in blue-deficient colors may contribute to a degradation of circadian stimulus. For example, the DuPont 72 and RAL 1015 each caused a reduction in the source's blue spectral component. This means that on a per-lumen basis, the blue content of the light is diminished relative to the other spectral components. In the most extreme case tested (the DuPont 72), the blue component did not reach the near-zero value of the source spectrum (Table 2).

It is likely that the direct sunlight component and inter-reflections from neutral floors and ceilings prevent a complete loss of blue light. Additionally, distance from the source (window) matters-a location closer to the window would have less degradation than one further away. The test room is 13'-0" deep [3962mm] perpendicular to the window. In the case of the DuPont 72, this distance was enough to result in a near-half reduction of blue light in a room painted with a blue-deficient color. These results confirm the findings of Wandachowicz (2006) that interior paint colors diminish the circadian efficacy of a light source through spectral distortions (Wandachowics 2006). These results tend to be specific for overcast conditions. This is because the effect of direct sunrays at the test location will likely diminish the contribution of interior reflections. 

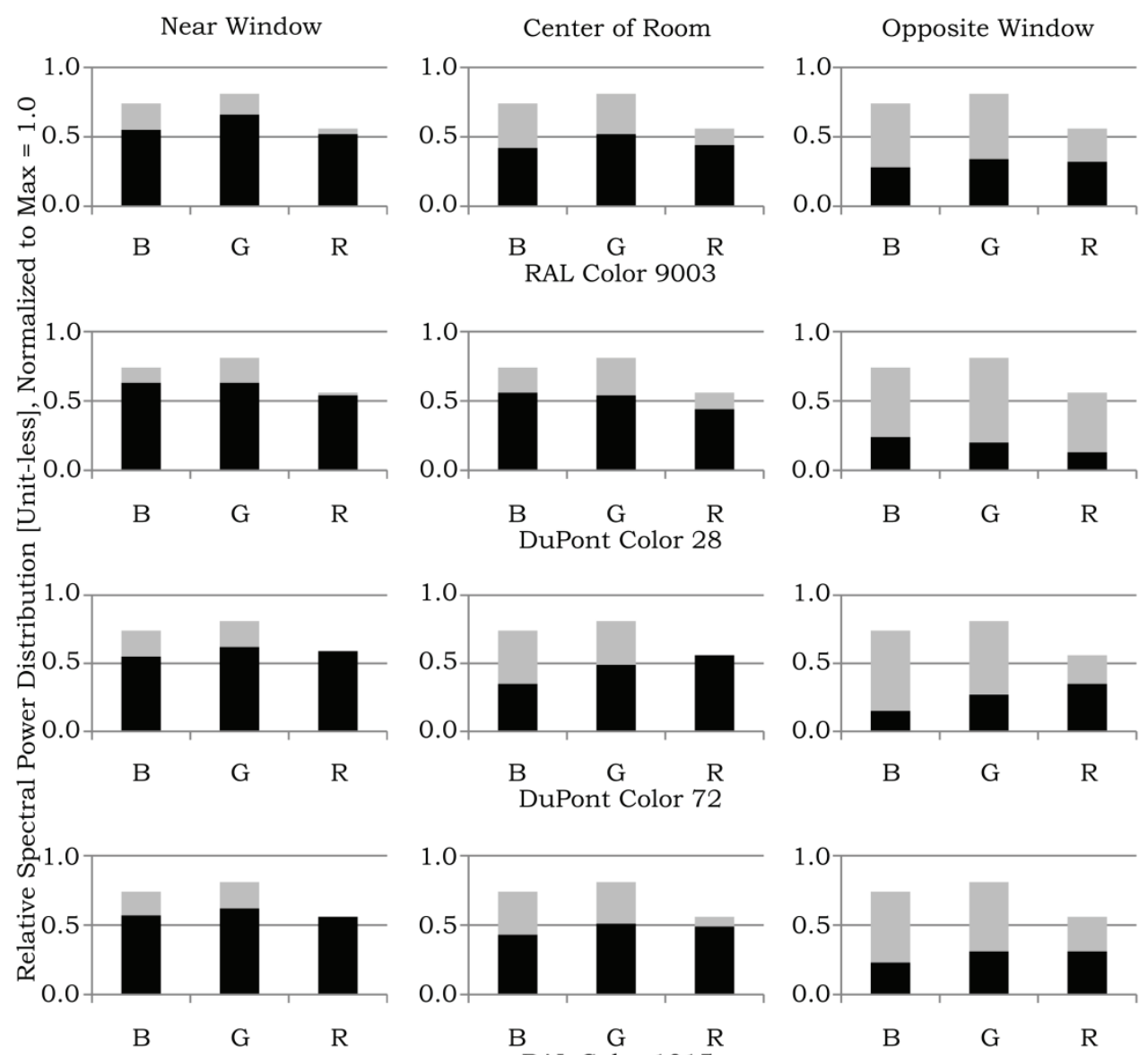

RAL Color 9003
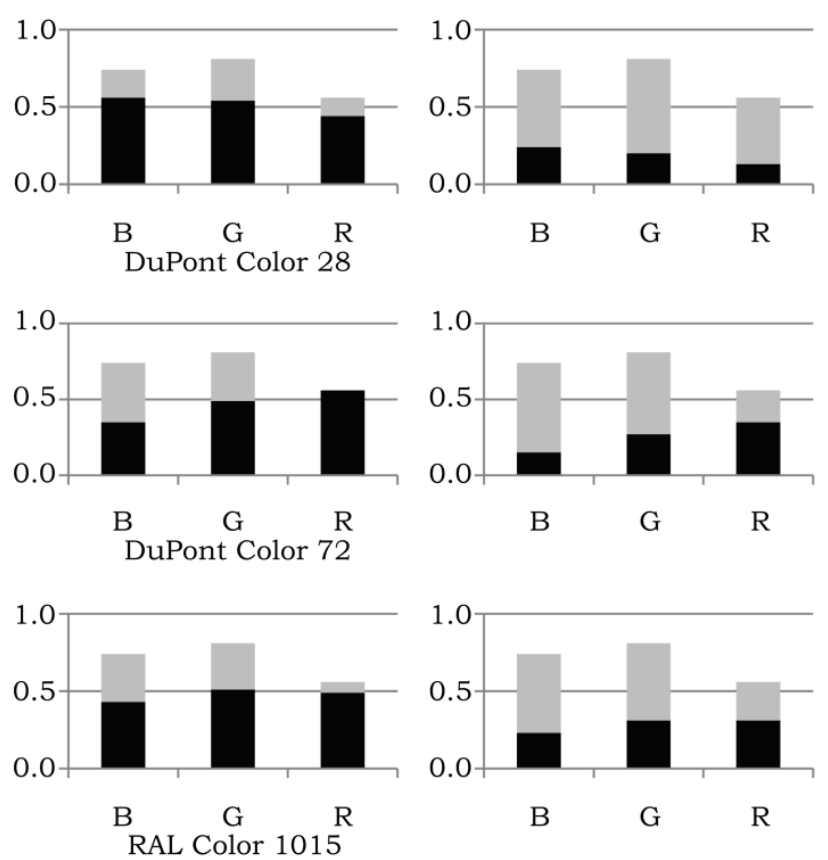

Fig. 11. Relative Radiometric RGB Values for Simulated Spectra, Normalized to 1.0, with Variations Based on Distance from Window (Light Source) and Interior Paint Color

\section{DISCUSSION}

One of the greatest advances of the modern era is the ability to construct buildings that are comfortable and brightly lit without regard to orientation and access to daylight (Banham 1984). The present research, however, indicates that the human circadian system may be more sensitive to these differences for optimal functioning, and suggests that additional considerations for circadian efficiency are required in addition to general building illumination, which serves a separate purpose than vision. The role of circadiansensitive design is gaining prominence through codification in the Green Guides for Health Care Design and, while initial results are promising, additional research in this area is required (Green Guide for Health Care 2007).

\subsection{ACHIEVING CIRCADIAN NEEDS}

Figure 4 represents a starting point for how illumination can meet circadian needs and provide a useful and novel tool for lighting and architectural designers. These model predictions remain to be tested experimentally and therefore remain a work-in-progress as additional 
information is accrued. Other considerations may also be necessary as these data are developed. For example, lighting spaces with lower levels of bluer light may not find acceptance from users based on color temperature preference. There may also be as yet unproven consequences on health and performance of altering light environments beyond normative conditions (Stevens and others 2007) (Lockley 2007) and therefore caution is required as these basic findings are applied in real-world settings.

The siting and orientation of a building may affect its ability to meet circadian-weighted Daylight Autonomy goals as indicated in Fig. 7. This is complicated in real-world applications by urban masking effects and the use of courtyards in buildings such as hospitals. So, the results of Fig. 7 cannot be applied to new building construction blindly. Instead, a careful analysis of solar access must also inform building massing and orientation.

The findings presented here add to discourse regarding the healthpromoting potential of building envelope design. A building's envelope is a significant investment in the appearance and functionality of a building and will tend to experience few replacement cycles during a building's lifespan (SLA 2007). These findings demonstrate that a room with a window is no guarantee of adequate circadian illumination. A highly transmissive window was tested in the present research $\left(\tau_{n}=0.74\right)$. Even in this case, the likelihood of achieving the modest target illumination level varied greatly, especially below $50 \%$ glazing fraction. Above $50 \%$, the circadian efficacy improvement for glazing fraction by orientation has diminishing return. Specific healthcare goals such as improved quality and/or cost savings, however, may dictate meeting circadian illumination targets at the highest rates. Conversely, tinted windows, which are more commonly used in the United States, often have transmissivities in the range of $50-60 \%$. This means that a larger window area may be necessary to achieve the same results as the clear window tested here. Tint colors such as bronze or gray will reduce the contribution of the blue light components of daylight, and it is these components that are most critical for circadian stimulus.

Artificial lighting, in its most common forms, cannot substitute for circadian illumination in most building applications. In comparison to building envelopes, artificial lighting systems are much less durable, more prone to replacement cycles (SLA 2007), and limited lamp-life dictates rapid cycling of lamps over the lifespan of a building. The intensity of artificial light will vary based on a number of circumstances including the building, system age, maintenance, design, and so on. In the case of the room studied, 300 lux horizontal/100 lux vertical was found to be inadequate in a temporally neutral application. Increasing illumination intensity solely to achieve circadian efficiency goals would likely raise interior cooling loads and electricity consumption. This is especially true for office buildings where power consumption for lighting and air 
conditioning represent a significant percentage of energy use. Alternately, it is theoretically possible to choose a bluer lamp that would meet basic circadian requirements for alertness at lower levels of illumination intensity (Fig. 4). This choice, however, would likely only result in user demands for higher illumination levels to maintain visual comfort. Furthermore, artificial light may lack the temporal qualities necessary for proper circadian function (Veitch and others 2004). Except for some specific emerging technologies, artificial illumination cannot substitute for the temporal cues (alerting, phase shifting, etc.) of daylighting, and used wrongly may, in fact, confound circadian organization. Not every situation needs to provide $100 \%$ circadian alerting potential. For example, family rooms, dining rooms and bedrooms in residences may benefit their occupants by providing no alerting effect (e.g., below the $25 \%$ line on Fig. 4), thus reinforcing the natural onset of melatonin in the early evening hours. Therefore, for most typical architectural applications, it makes sense to use appropriate exposure to daylight to reinforce good circadian entrainment. Balance is needed, however, as more daylight may lead to more glare, and exposure may also be impacted by user behavior. As Fig. 10 demonstrates, use of window blinds may reduce the circadian efficacy of daylight. Mitigating approaches could include less opaque window blind systems and better window and shading device design.

\subsection{FURTHER INTERIOR SPACE CONSIDERATIONS}

The arrangement of building interiors (walls, furniture, etc.) can also contribute to, or detract from, the circadian stimulus of daylight. For example, Fig. 8 demonstrates that small variations in patient positioning in the subject room can result in large changes in access to the daylight illumination goal. In an extreme case (IESNA RP-2906, Fig. 7) for example, the patient clearly faces away from the window altogether, and likely receives little or no circadian benefit (IESNA 2006). These experimental results find immediate application to the question of patient room toilet location in hospitals. In cases where a room's toilet is located on the façade-size of the space, access to daylight is reduced through lower glazing fraction (Fig. 7) and through distance from the window (Fig. 9).

More broadly, the same techniques can find application to design of other parts of a hospital, such as clinical and ancillary areas, and to other building types such as office buildings and residences. For example, doctors often work in largely windowless clinics. Using the techniques described in this paper, a designer could propose new designs for clinics which allow for adequate daylighting in work areas, thus reinforcing the circadian synchrony of doctors and other medical staff, with additional anticipated benefits resulting from the alerting potential of daylight. Similarly, for office spaces, southern exposures may enhance the sensation of alertness and improve performance over the duration of the average workday, in contrast to eastern and 
western exposures which will tend to have better light at the beginnings and ends of workdays.

In the context of homes and for individuals with normal sleep-wake patterns, exposure to bright morning daylight in bedrooms, and daytime daylight in other rooms both makes sense and has been suggested both from a functional and circadian perspective (Alexander and others 1977). In typical multifamily residences, where each unit typically has a single exposure, the potential circadian effect would be dependent on the orientation of the entire apartment (Fig. 12). As orientation is rarely considered in apartment design, it may make sense to rethink societal templates for these housing types to offer functionally-appropriate solar exposures for each unit.

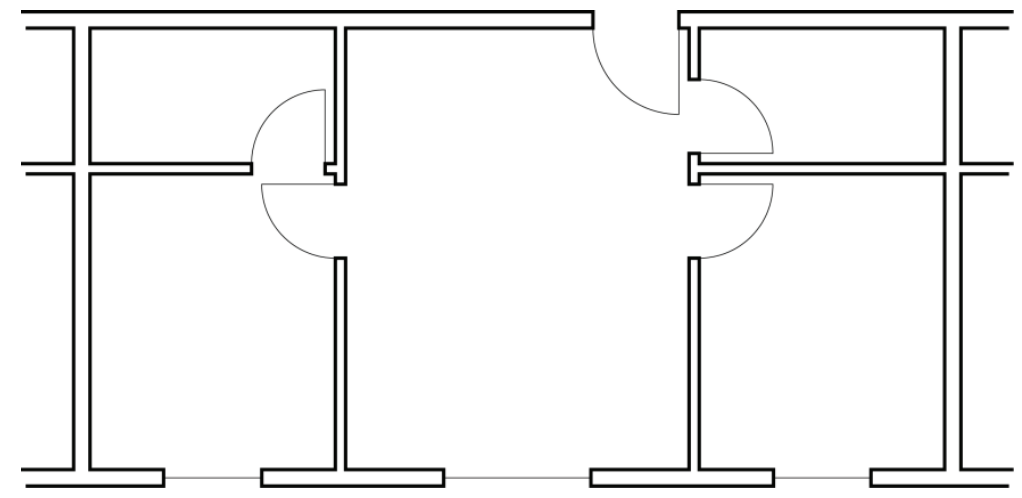

Fig. 12. Typical Two-Bedroom Apartment in the US

These results also find application in interior design. Much of the literature on the psychology of color and the role of color and light on human health postulate that reddish (longer-wavelength) colors are stimulating and short-wavelength bluish colors are calming, including use in hospital color-based therapeutics (Itten 2003). Such thinking is grounded in ancient and mediaeval medicine, and more recently in the field of 'color therapy' with little or no controlled experimental support. The recent work on the alerting effects of light (Cahochen and others 2005) (Lockley and others 2006), supported by the results of Experiment 3, show that the opposite is the case: short-wavelength blue light is most arousing neurobehaviorally and longer-wavelength light is less stimulating. Johannes Itten writes about the stimulating effects of reddish colors compared to the calming effects of bluish colors, and suggests this consideration in hospital color-based therapeutics (Itten 2003). Experiment 3 overturns his suggestions. A room with predominantly red or red-shifted finishes will likely result in a reduction in the circadian efficacy of the light sources, especially at some distance from the window. This means that red-shifted finishes can reduce or eliminate the circadian effect of light sources. Recent trends in healthcare design emphasize a "homey" appearance with artificial natural finishes and "warm" color pallets. Besides being conceptually inviolate, this also may conflict with the physiological results reported here-especially in spaces with already marginal daylight contribution. 


\subsection{LIMITATIONS OF EXISTING TOOLS}

Simulating both the spectrum and intensity of light is beyond the capabilities of all but the most advanced computer modeling software. Successful simulation of light effects on circadian and other nonvisual responses requires an understanding of both, however.

While RADIANCE is used as a 3-channel ray tracer in this paper, this approach is not without limitations. Used to simulate and compare relative radiometric spectra, this approach does not allow for the direct addition of results from separate simulation results as in Wandachowicz (2006) (Wandachowics 2006). Ward and EydelbergVileshin (2002) draw attention to the fact that the number of channels necessary to simulate a continuous spectrum is not clear

(Ward \& Eydelberg-Vileshin 2002). Wandachowicz used three separate simulations ( 3 simulations X 3 channels) to mimic a 9channel ray tracer. This proved to have a lower error than using RADIANCE as a 3-channel ray-tracer alone, when error was calculated based on differences in illuminance results (Wandachowics 2006). The research presented here, however, only uses the resultant RGB values to determine spectral shift caused by inter-reflections, not for predicting illuminance values.

DAYSIM assumes an even spectrum, and cannot be used to simulate the sun's ever-changing apparent color temperature. The calculation of DA requires an illuminance goal, and so we here used our best judgement in choosing a value whose circadian-illuminance weighting would most adequately reflect the conditions of various orientations. For instance, north façades will receive bluer light, and so our choice was for a D75-based illuminance target. Daylight autonomy calculation also requires specification of a constant daily daylit period without regard for variations in sunrise and sunset times. The choice of a $12 \mathrm{~h}$ day is thus a compromise in this regard.

\section{CONCLUSIONS}

This paper provides a preliminary method for the analysis of circadian illumination in a space with certain assumptions. The method presented uses off-the-shelf technology and some novel calculations to provide useful design information. The results of the experiments above indicate that for a given architectural design, the large and small decisions each contribute to, or detract from, the relative circadian potential of a space. Untested, but likely, is the fact that these variables work in series, starting with sky conditions proceeding to the eye, with each decision affecting the next proportionally.

This paper does not attempt to conclusively define circadian stimulus-rather, it raises critical questions about the design of buildings and lighting with respect to improving human health and healthcare outcomes. Towards this end, it harnesses what knowledge is available to sketch-out processes and key findings by which we may better understand the implications for buildings. 
Little in the way of rigorous analysis exists in the emerging field of evidence-based design, however billions of dollars are committed to healthcare construction in the United States each year. This paper applies traditional scientific inquiry in an attempt to provide objective, quantitative analysis of specific health characteristics of light to arrive at specific recommendations for architectural design. Careful attention to the issues presented here should increase the circadian health potential of new building designs, and will likely contribute to improve patient outcomes pending validation through future research.

\section{ACKNOWLEDGEMENTS}

Christopher Pechacek was supported by the U.S. Air Force and the Massachusetts Institute of Technology (MIT) and Dr. Marilyne Andersen by the MIT for this work. Dr. Steven W. Lockley was supported in part by the National Center for Complementary and Alternative Medicine and the National Space Biomedical Research Institute through NASA NCC 9-58.

\section{DISCLAIMERS}

The views expressed in this article are those of the author and do not reflect the official policy or position of the U.S. Air Force, Department of Defense, or the U.S. Government.

\section{APPENDIX}

Equations 1 through 4, below, are used to calculate the circadian efficacy of an illuminant in a temporally neutral application. For the purposes of this paper, Microsoft's EXCEL was used to perform these calculations, so the equations are expressed in tabular form.

Equation 1 defines a unit-less photometric response from a unit-less radiometric spectra. The sum of the photometric response [unit-less], in this case, is $1,124,462$ which is used as part of the scalar factor in Equation 2.

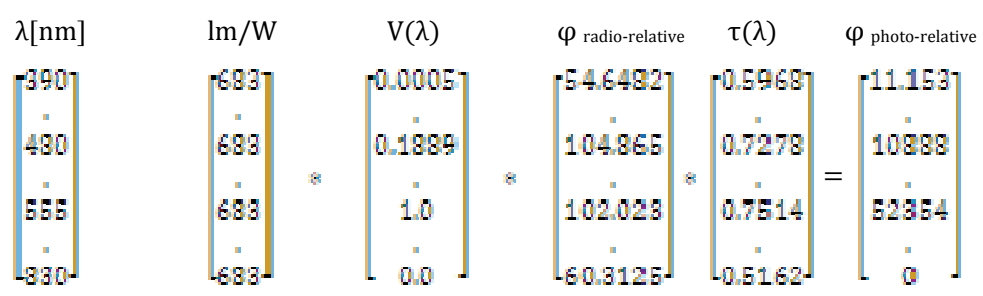

Given an illuminance, say 1000 lux, the ratio of photometric response at defined increments (here $5 \mathrm{~nm}$ ) to the total photometric response [unit-less] are used to infer the actual illuminance per increment (Equation 2). Summing the resultant column should produce the equation's input value: 1000 lux.

$$
\lambda[\mathrm{nm}] \quad \varphi_{\text {photo-relative }} \quad \Sigma \varphi_{\text {photo-relative }} \quad \mathrm{E}[\operatorname{lm}] \quad \varphi_{\text {photo-absolute }}[\operatorname{lux}]
$$




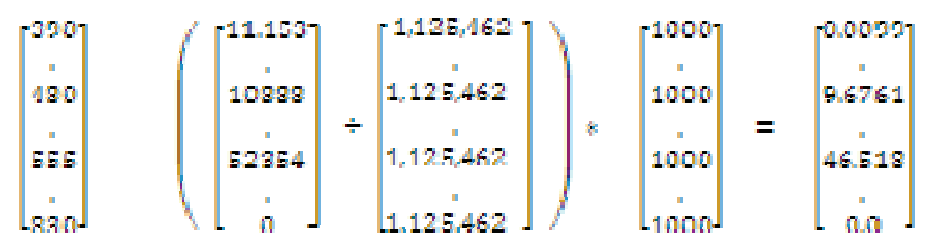

Using the same scalar factors as in Equation 2 above, the unit-less radiometric spectrum is converted to an actual spectral power distribution in Watts as shown in Equation 3. Summing the resultant column, in this case, results in $4.56 \mathrm{~W} / \mathrm{m}^{2}$.

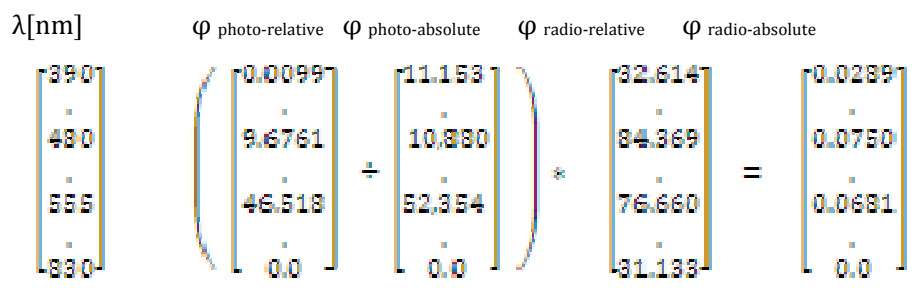

Equation 4 Transforms the radiometric spectrum into circadian stimulus in Watts $[\mathrm{W}-\mathrm{C}(\lambda)]$. The sum of the resultant column, in this case, is $1.45 \mathrm{~W}-\mathrm{C}(\lambda)$.

$$
\begin{aligned}
& \lambda[\mathrm{nm}] \quad \varphi_{\text {radio-absolute }} \mathrm{C}(\lambda) \quad \mathrm{W}-\mathrm{C}(\lambda)
\end{aligned}
$$

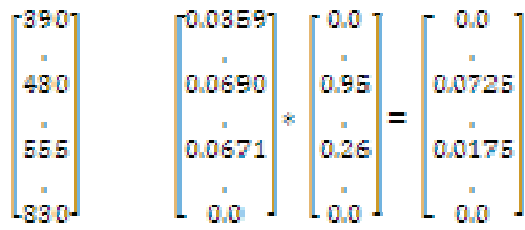

For the RADIANCE simulations used to test spectral neutrality, the following material parameters were used.

The radiometric daylight conditions were set as described below for an overcast sky (D75):

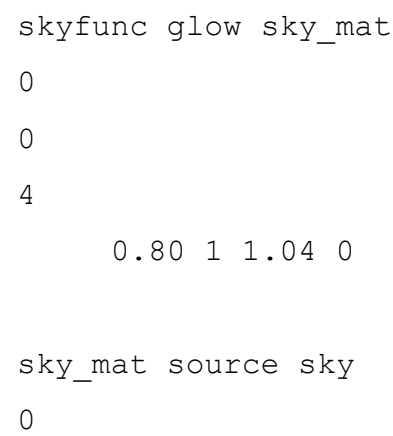


The radiometric material properties were set as described below:

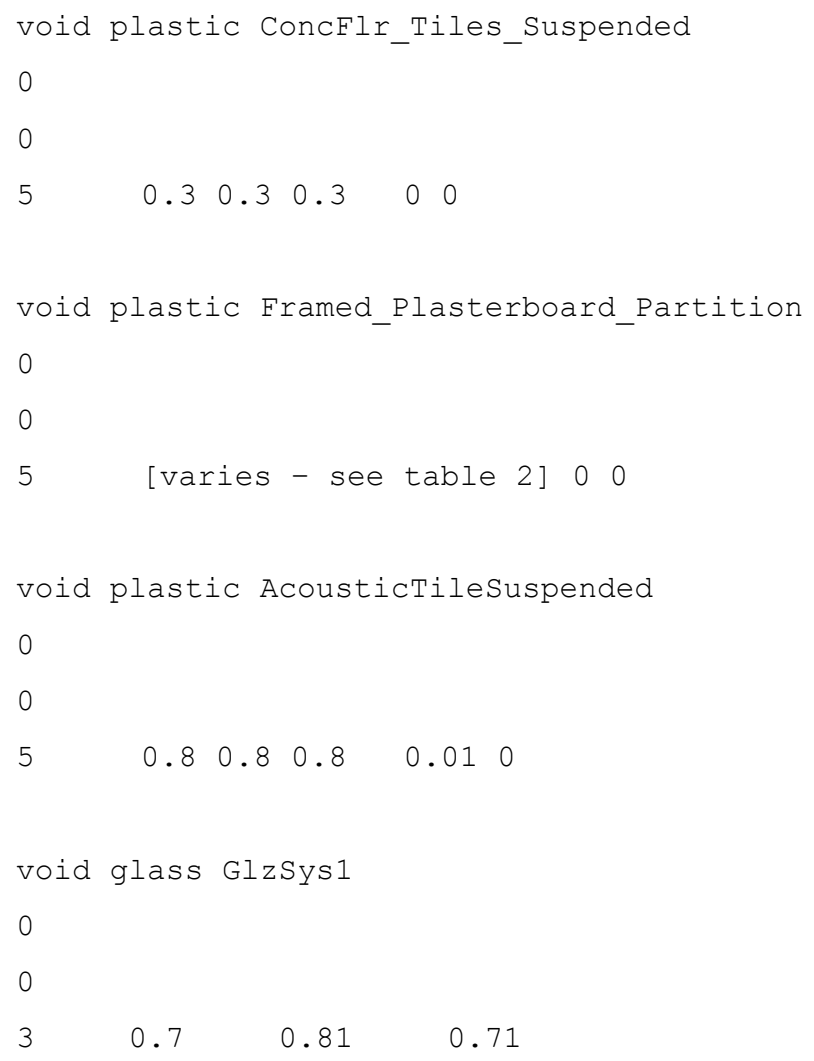

\section{REFERENCES}

Alexander C, Ishikawa S, Silverstein M, Jacobson M, Fiksdahl-King I, \& Angel S. 1977. A Pattern Language: Towns Buildings Construction.

American Institute of Architects. 2006. Guidelines for Design and Construction of Health Care Facilities.

ASTM International. 2006. Standard Practice for Computing the Colors of Objects by Using the CIE System. West Conshohocken, PA: ASTM International.

Banham R. 1984. The Architecture of the Well-tempered Environment. 2nd ed. Chicago, IL, USA: The University of Chicago Press.

Beauchemin KM \& Hays P. 1998. Dying in the Dark: Sunshine, Gender and Outcomes in Myocardial Infarction. J Royal Soc Medicine. 91:352-354. 
Bergman RS, Parham TG, \& McGowan TK. 1995, Winter. UV Emission from General Lighting Lamps. J Illumin Engin Soc. 24(1):13-24.

Brainard GC \& Hanifin JP. 2005. Photons, Clocks and Consciousness. J Biological Rhythms. 20(4):314-325.

Brainard GC, Hanifin JP., Greeson, J. M., Byrne, B., Glickman, G., Gerner, E., et al. 2001. Action Spectrum for Melatonin Regulation in Humans: Evidence for a Novel Circadian Photoreceptor. J Neurosci. 6406-6412.

Building Technologies Department, LBNL. 2003. Materials. (Lawrence Berkeley National Laboratory) Retrieved 10 09, 2007, from The RADIANCE 3.5 Synthetic Imaging System: http: / / radsite.lbl.gov/radiance/refer/ray.html

Building Technologies Department LBNL. n.d. Optics 5 Version 5.1. Berkeley, CA.

Cajochen C, Munch M, Kobialka S, Krauchi K, Steiner R, Oelhafen P, et al. 2005. High Sensitivity of Human Melatonin, Alertness, Thermoregulation and Heart Rate to Short Wavelength Light. J. Clin. Endocrinol. Metab. 90:1311-1316.

Cajochen C, Zeitzer JM, Czeisler CA, \& Dijk DJ. 2000. Dose-Response Relationship for Light Intensity and Ocular and Electroencephalograpic Correlates of Human Alertness. Behavioural Brain Research 115:75-83.

Christakou DE \& Amorim CN. 2005. Daylighting Simulation: Comparison of Softwares for Architect's Utilization. Ninth International IBPSA Conference. Montreal.

[CIE]. Commission Internationale de 1'Eclairage 2006. Colorimetry Part 2:CIE Standard Illuminants.

Czeisler CA, Duffy JF, Shanahan TL, Brown EN, Mitchell JF, Rimmer DW, et al. 1999. Stability, Precision and Near-24-Hour Period of the Human Circadian Pacemaker. Science 284(5423):2177-81.

Farley KM \& Veitch JA. 2001. A Room with a View: A Review of the Effects of Windows on Work and Well-Being. Institute for Research in Construction.

Green Guide for Health Care. 2007. Retrieved from http://www.gghc.org/

Gronfler C, Wright JK, Kronauer RE, Jewett ME, \& Czeisler CA. 2004. Efficacy of a Single Sequence of Intermittent Bright Light Pulses for Delaying Circadian Phase in Humans. Am J Physiol Endrinol Metab 287:E174-181.

Hausladen G, de Saldanha M, Liedl P, \& Sager C. 2005. Climate Design: Solutions for Buildings that Can Do More with Less Technology. O'Toole Ed, \& R Peat Trans. Munich, Germany: Birkauser. 
[IESNA] Illuminating Engineering Society of North America. 2006. Lighting for Hospitals and Health Care Facilities. New York, NY.

Itten, J. 2003. The Elements of Color (1961). E Van Hagen, Trans. Stuttgart, Germany: John Wiley \& Sons.

Joseph A. 2006. The Impact of Light on Outcomes in Healthcare Settings. Issue Paper \#2.

Kleindienst S, Bodart M, \& Andersen M. 2008. Graphical Representation of Climate-Based Daylight Performance to Support Architectural Design. Leukos. In press.

Knez I. 2001. Effects of Colour of Light on Nonvisual Psychological Processes. J Environ Psych. 21:201-298.

LeProult R, Colecchia EF, L'Hermite-Beleriaux M, \& Van Cauter E. 2001. Transition from Dim to Bright Light in the Morning Induces an Immediate Elevation of Cortisol Levels. J Clin Endocrinol Metab. 86(1):151-157.

Lewy AJ, Sack RL, \& Singer CM. 1985. Melatonin, Light and Chronobiological Disorders. In Ciba Foundation Symposioum 117:

Photoperiodism, Melatonin and the Pineal (pp. 231-252). London, UK: Pitman.

Lockley SW. 2008, In Press. Influence of Light on Circadian Rhythmicity in Humans. In L. R. Squire (Ed.), Encyclopaedia of Neuroscience. Oxford, UK.

Lockley SW. 2007. Safety Considerations for the Use of Blue-Light Blocking Glasses in Shift-Workers. J Pineal Res. 42(2):210-1.

Lockley SW \& Gooley JJ. 2006. Circadian Photoreception: Spotlight on the Brain. Current Biology R795-797.

Lockley SW, Brainard GC, \& Czeisler CA. 2003. High Sensitivity of the Human Circadian Melatonin Rhythm to Resetting by Short Wavelength Light. J Clin Endocrinol Metab. 88(9): 4502-4505.

Lockley SW, Evans EE, Scheer FA, Brainard GC, Czeisler CA, \& Aeschbach D. 2006. Short-Wavelength Sensitivity for Direct Effects of Light on Alertness, Vigilance and Waking Electroencephalogram in Humans. Sleep. 161-168.

Lockley SW, Skene DJ, Butler LI, \& Arendt J. 1999. Sleep and Activity Rhythms are Related to Circadian Phase in the Blind. Sleep 22(5):616-23.

Lockley SW, Skene DJ, Tabandeh H, Bird AC, \& Defrance R. 1997. Relationship Between Melatonin Rhythms and Visual Loss in the Blind. J Clin Endocrinol Metab. 82(11):3763-70.

Mahdavi A, Berberidou-Kallivoka L. 1993. A Two-Way Inference Approach to Daylighting Simulation. J Illumin Eng Soc. 22(1):66-74. 
Mills PR, Tomkins SC, \& Schlangen LJ. 2007. The Effect of High Correlated Colour Temperature Office Lighting on Employee Wellbeing and Work Performance. J Circadian Rhythms. 5 (2).

Neutra R. 2007. Survival Through Design (1954). In WW Braham, JA Hale, \& JS Sadar, Rethinking Technology: A Reader in Architectural Theory (pp. 117-126). New York, NY, USA: Routledge.

Pechacek CS, Andersen M, \& Lockley SW. 2008. Combining Annual Daylight Simulation with Photobiology Data to Assess the Relative Circadian Efficacy of Interior Spaces. Proceedings of the eSim 2008 Conference.

Peirson S. \& Foster RG. 2006. Melanopsin Another Way of Signaling Light. Neuron. 49(3): 331-339.

Perez R, Seals R, \& Michalsky J. 1993. All-Weather Model for Sky Luminance Distribution - Preliminary Configuration and Validation. Solar Energy. 50(3):235-245.

Philips Lighting. http:/ /www.lighting.philips.com/gl_en/news/press/sector/2005/wel ness_lighting.php

Phipps-Nelson J, Redman JR, Dijk DJ, \& Rajaratnam SM. 2003. Daytime Exposure to Bright Light, as Compared to Dim Light, Decreases Sleepiness and Improves Psychomotor Vigilance Performance. Sleep. 26(6):695-700.

Provencio I, Rodriguez IR, Jiang G, Hayes WP, Moreira EF, \& Rollag MD. 2000. A Novel Human Opsin in the Inner Retina. The Journal of Neuroscience. 20(2):600-606.

Reinhart C. 2006. Tutorial on the Use of Daysim for Sustainable Design. Retrieved from http://irc.nrccnrc.gc.ca/ie/lighting/daylight/daysim_e.html

Reinhart C. \& Walkenhorst W. 2001. Validation of Dynamic RADIANCE-based Daylight Simulations for a Test Office with External Blinds. Energy and Buildings. 33(7):683-697.

Ruger M, Gordijn MC, Beersma DG, de Vries B, \& Daan S. 2006. Time-of-Day-Dependent Effects of Bright Light Exposure on Human Psychophysiology: Comparison of Daytime and Nighttime Exposure. Am J Physiology: Regulatory, Integrative and Comparative Physiology. 290:1413-1420.

Ruger M, Gordijn M, Beersma DG, de Vries B, \& Daan S. 2005. Weak Relationships Between Suppression of Melatonin and Suppression of Sleepiness/Fatigue in Response to Light Exposure. J. Sleep Res. 14:221-227.

Scheer FA, \& Hiujs RM. 1999. Light Affects Morning Salivary Cortisol in Humans. J Clin Endocrinol Metab. 84(9):3395-3398. 
Sharpe LT, Stockman A, Jagla W, \& Herbert J. 2005. A Luminous Efficiency Function, $\mathrm{V}^{*}$ (lambda), for Daylight Adaptation. J Vision. 5:948-968.

SLA. 2007. Changing Speeds. In WW Braham, JA Hale, \& JS Sadar, Rethinking Technology: A Reader in Architectural Theory (pp. 437439). New York, NY, USA: Routledge.

Stevens RG, Blask DE, Brainard GC, Hansen J, Lockley SW, Provencio I, et al. 2007. Meeting Report: The Role of Environmental Lighting on Circadian Disruption in Cancer and Other Diseases. Environ Health Prospect. 115(9):1357-62.

Stockman A, \& Sharpe LT. 2000. The Spectral Sensitivities of the Middle- and Long-Wavelength-Sensitive Cones Derived from Measurements in Observers of Known Genotype. Vision Res. 40(13):1711-1737.

Thapan K, Arendt J, \& Skene D. 2001. An Action Spectrum for Melatonin Suppression: Evidence for a Novel Non-Rod, Non-Cone Photoreceptor System in Humans. J Physiology. 535(1):261-267.

Vandewalle G, Balteau E, Phillips C, Degueldre C, Moreau V, Sterpenich V. 2006. Daytime Light Exposure Dynamically Enhances Brain Responses. Current Biology. 16:1616-1621.

Veitch JA, van den Beld G, Brainard G, \& Roberts JE. 2004. Ocular Lighting Effects on Human Physiology and Behaviour. CIE Publication 158. Vienna, Austria.

Walsh JM, Rabin BS, Day R, Williams JN, Choi K, \& Kang JD. 2005. The Effect of Sunlight on Postoperative Analgesic Medication Use: A Prospective Study of Patients Undergoing Spinal Surgery. Psychosomatic Medicine. 67(1):156-163.

Wandachowics K. 2006. Calculation of the Circadian Illuminance Distribution with Radiance. Retrieved 2007, from http: / /www.radiance-online.org/radianceworkshop5/2006_Radiance_Workshop/Presentations/Wandachowicz -2_RW2006.pdf

Ward G, \& Eydelberg-Vileshin E. 2002. Picture Perfect RGB Rendering Using Spectral Prefiltering and Sharp Color Primaries. In P. Debevec, \& S. Gibson (Ed.), Thirteenth Eurographics Workshop on Rendering.

Wehr TA. 2001. Photoperiodism in Humans and Other Primates: Evidence and Implications. J Biol Rhythms. 16(4):348-64.

Wilson LM. 1972. Intensive Care Delirium. Archives of Internal Medicine. 130:225-226.

Zeitzer JM, Dijk DJ, Kronauer RE, Brown EN, \& Czeisler CA. 2000. Sensitivity of the Human Circadian Pacemaker to Nocturnal Light: Melatonin Phase Resetting and Suppression. J Physiology. 526(3):695-702. 
Zeitzer JM, Khalsa SB, Boivin DB, Duffy JF, Shanahan TL, Kronauer RE, et al. 2005. Temporal Dynamics of Late-Night Photic Stimulation of the Human Circadian Timing System. Am J Physiology: Regulatory, Integrative and Comparative Physiology. 289:839-844. 